\title{
Hardscrabble Wind Power Project
}

\section{Methods}

Research Fellow:

Aidan Ackerman

Assistant Professor

SUNY ESF

Robin Hoffman

Associate Professor

SUNY ESF

Maren King

Associate Professor

SUNY ESF

Research Assistant:

Meaghan Keefe

MLA Candidate

SUNY ESF

\section{Firm Liaison:}

Gordon Perkins

Senior Project Manager

Environmental Design and Research

This investigation was conducted as part of the Landscape Architecture Foundation's 2019 Case Study Investigation (CSI) program. CSI matches faculty-student research teams with design practitioners to document the benefits of exemplary high-performing landscape projects. Teams develop methods to quantify environmental, social, and economic benefits and produce Case Study Briefs for LAF's Landscape Performance Series.

To cite: Ackerman, Aidan, Robin Hoffman, Maren King, and Meaghan Keefe. "Hardscrabble Wind Power Project Methods." Landscape Performance Series. Landscape Architecture Foundation, 2019. https://doi.org/10.31353/cs1541

The full case study can be found at: https://landscapeperformance.org/case-studybriefs/hardscrabble-wind-power-project 


\section{Environmental Benefits}

- Restored approximately 20,000 sf of existing wetland that was impacted by the project and created an additional 28,300 sf. This mitigation to impact ratio of 2.4 to 1 exceeds the local and state requirement of 1.5 to 1.

Methods: Data from four long-term wetland monitoring sample points within the wind farm project site were compared to calculate the net increase in wetland area as a result of the project. This data comes from monitoring documents that were collected by the landscape architect at four monitoring sample points over six years post-construction.

The first year of wetland monitoring occurred immediately post-construction of the wind farm, and no wetland species were prevalent. In contrast, by the sixth year of post-construction monitoring, the study showed a high prevalence of native vegetation, as evidenced by the notation of widespread Obligate Wetland Species (OBL) at the four sampling locations. OBL species have an over $99 \%$ probability of being found in wetlands under natural conditions.

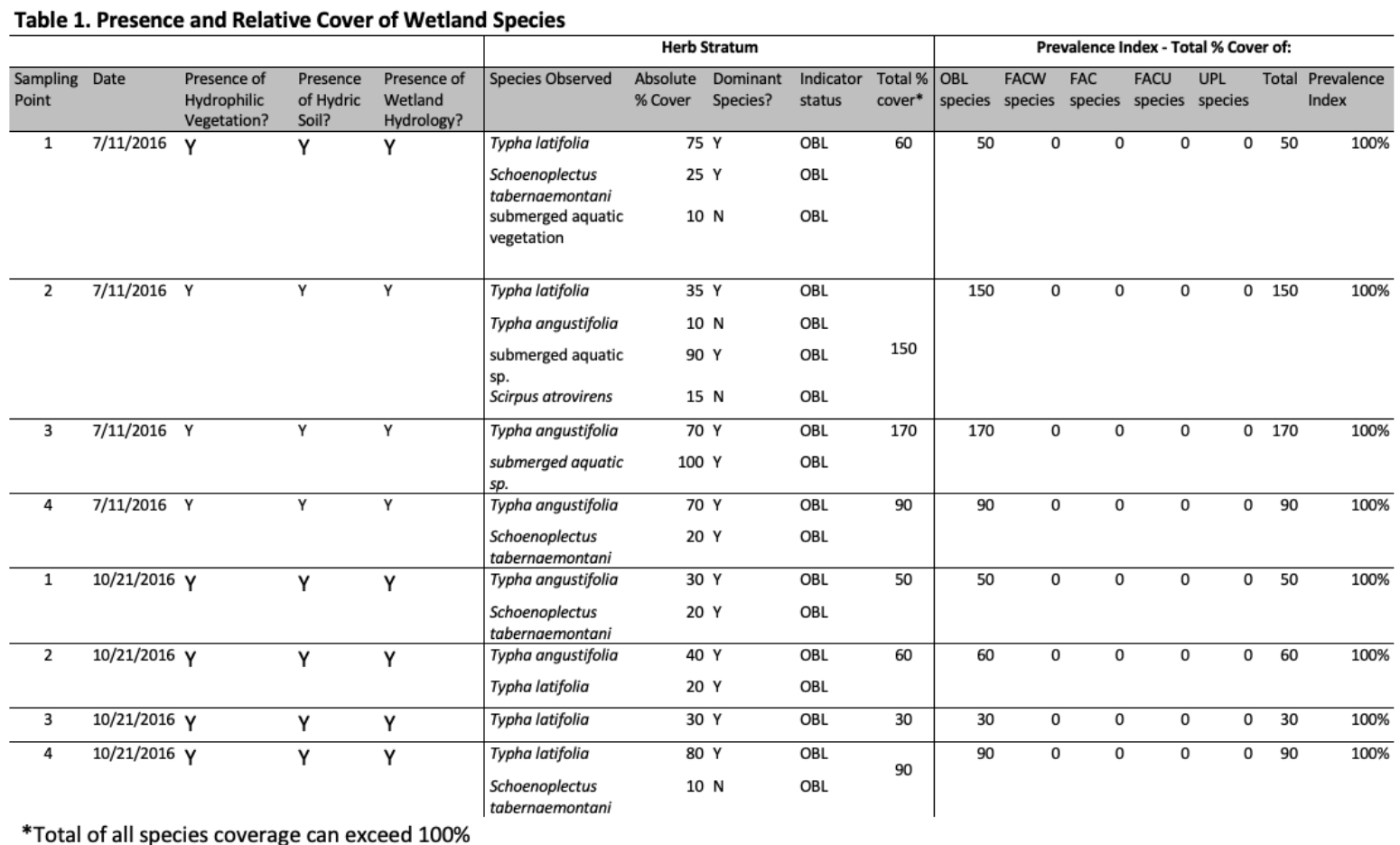

Table 1. Sixth year wetland monitoring report showing indicators of OBL species and a $100 \%$ prevalence index at all four monitoring sites. 


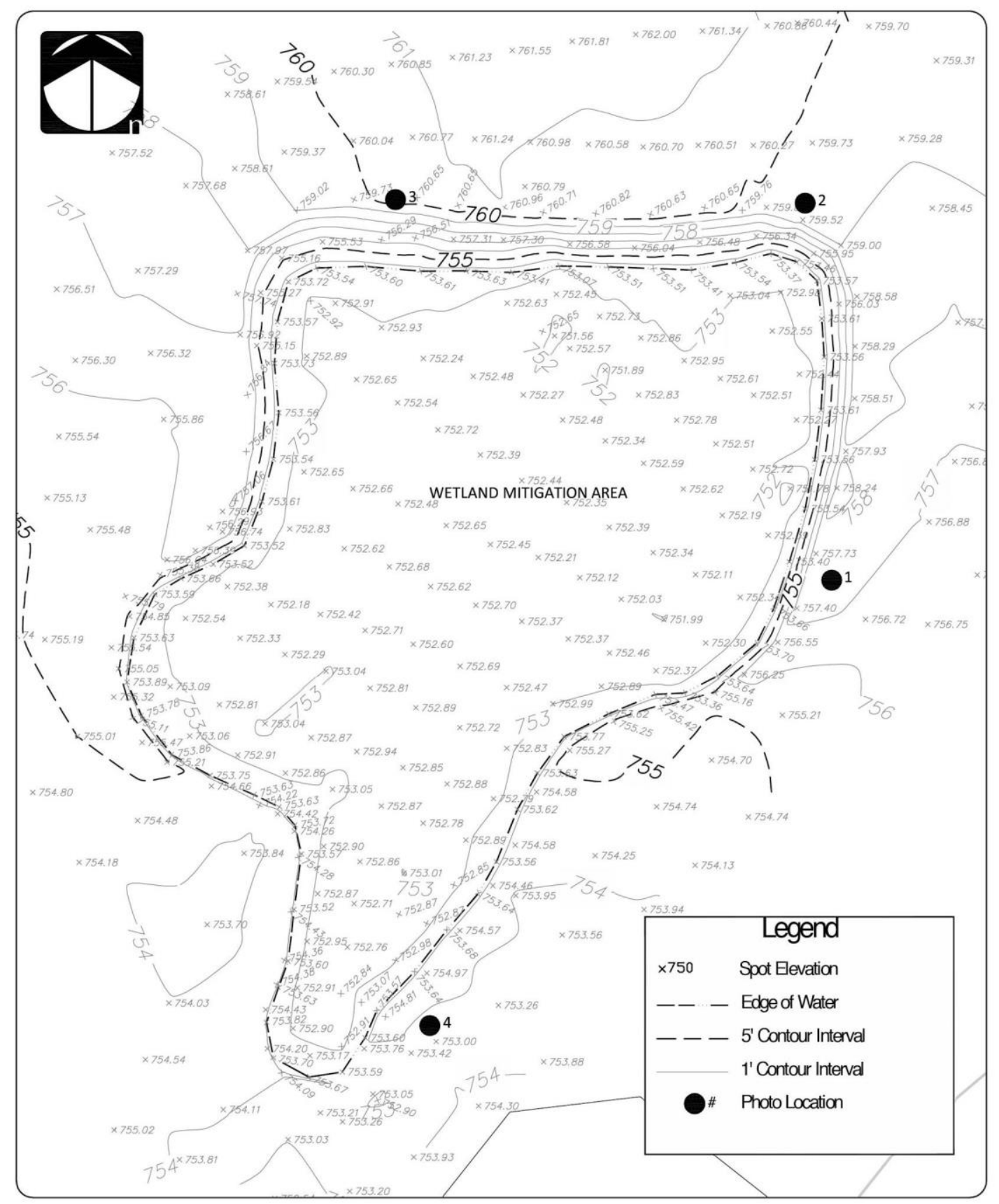

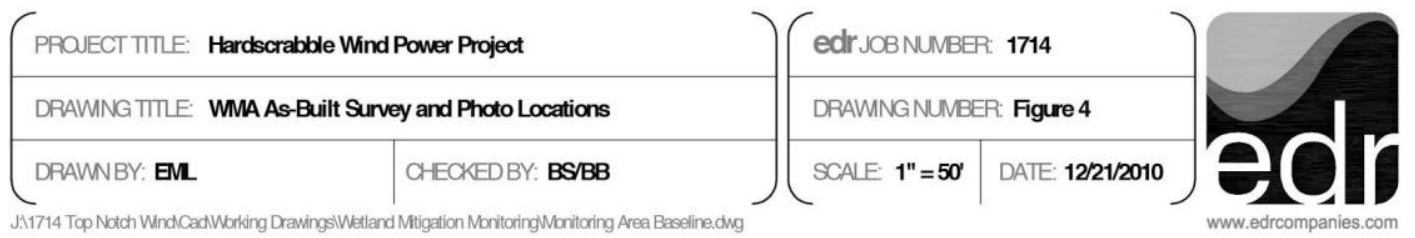

Figure 1. Plan showing the locations of the four wetland observation sites, where sample data was collected over a six-year monitoring period. 
Calculations:

A 20,000-sf area was impacted by the project. This area was restored and an additional 28,300 sf of wetland was created.

20,000 square feet of existing wetland $+28,300$ square feet of added wetland area $=\mathbf{4 8 , 3 0 0}$ square feet of total wetland area post-construction

48,300 total square feet of wetland / 20,000 square feet of existing wetland impacted $=\mathbf{2 . 4}$ final mitigation impact ratio

This exceeds the minimum mitigation impact ratio of 1.5 to 1 (mitigation to impact), with a final mitigation impact ratio of 2.4 to 1 (mitigation to impact). The ratio of 1.5 to 1 is based on the requirements for mitigation of wetland impact outlined in the Final Rule of the U.S Army Corps of Engineers Compensatory Mitigation for Losses of Aquatic Resources.

\section{Sources:}

Environmental Design \& Research Landscape Architecture Planning, Environmental Services, Engineering and Surveying, P.C., 2010. "Compensatory Wetland Mitigation Plan".

Environmental Design \& Research Landscape Architecture Planning, Environmental Services, Engineering and Surveying, P.C., 2011. "Wetland Mitigation Area Monitoring Report".

Environmental Design \& Research Landscape Architecture Planning, Environmental Services, Engineering and Surveying, P.C., 2016. "Wetland Mitigation Area Status Report".

New York State Department of Environmental Conservation, 1995. "New York State Freshwater Wetlands Delineation Manual". https:/www.dec.ny.gov/docs/wildlife pdf/wdelm"an.pdf

\section{Limitations:}

Research was conducted more than five years ago by the landscape architect and not the CSI research team. Although the research is reliable, it is focused solely on counting species prevalence, and omits other observations such as in-depth soil and water testing which could contribute to a broader understanding of the wetland's restoration. Additionally, although monitoring was done each year for six years, the CSI research team only had access to the final year of monitoring reports, limiting the degree to which we could understand the growth trajectory of the wetland over the entire six-year period.

- Supports biodiversity with at least 3 bird species, 1 mammalian species, and 2 amphibian species observed in the site's wetland area.

Methods: Data were collected from four long-term monitoring sample points that were established in the Wetland Mitigation Area (WMA) during the Year 1 monitoring period (See 
Figure 1). These data were collected over a period of 6 years post-construction. During each site visit, information on soil conditions and wildlife observations were collected and the boundaries of the developing WMA were delineated in the field and mapped using a handheld GPS unit.

Species actually observed on site included muskrat (Ondatra zibethica), bullfrog (Rana catesbeiana), green frog (Rana clamitans), blue jay (Cyanocitta cristata), and American bittern (Botaurus lentiginosus). The American bittern was observed during both sampling visits, plus a third visit with representatives of the USACE, indicating that it resides, and could possibly be nesting, in the WMA. Deer tracks were also observed along the edge of the WMA and a turkey vulture (Cathartes aura) was seen flying overhead.

Other wildlife species considered likely to occur, based on the presence of suitable habitat and observations in previous years, include red-winged blackbird (Agelaius phoeniceus), American kestrel (Falco sparverius), wood duck (Aix sponsa), swamp sparrow (Melospiza georgiana), eastern kingbird (Tyrannus tyrannus), American crow (Corvus brachyrhynchos), eastern painted turtle (Chrysemys picta), snapping turtle (Chelydra serpentina), northern water snake (Natrix sipedon), green heron (Butorides virescens), and spring peeper (Pseudacris crucifer). The WMA also supports a variety of insects, and aquatic invertebrates, including damselflies, dragonflies, water boatman, and water striders.

\begin{tabular}{|c|c|c|c|c|c|}
\hline $\begin{array}{l}\text { Sampling } \\
\text { Point }\end{array}$ & Date & $\begin{array}{l}\text { Presence of } \\
\text { Hydrophilic } \\
\text { Vegetation? }\end{array}$ & $\begin{array}{l}\text { Presence of } \\
\text { Hydric Soil? }\end{array}$ & $\begin{array}{l}\text { Presence of } \\
\text { Wetland } \\
\text { Hydrology }\end{array}$ & Animal Species Observed (seen or heard) \\
\hline 1 & $7 / 11 / 2016$ & $\mathrm{Y}$ & Y & Y & leopard frog, American bittern, bullfrog, muskrat \\
\hline 2 & $7 / 11 / 2016$ & $\mathrm{Y}$ & Y & $\mathrm{Y}$ & muskrat \\
\hline 3 & $7 / 11 / 2016$ & $\mathrm{Y}$ & $\mathrm{Y}$ & $\mathrm{Y}$ & \\
\hline 4 & $7 / 11 / 2016$ & $\mathrm{Y}$ & $\mathrm{Y}$ & $\mathrm{Y}$ & \\
\hline 1 & $10 / 21 / 2016$ & $\mathrm{Y}$ & $\mathrm{Y}$ & $\mathrm{Y}$ & \\
\hline 2 & $10 / 21 / 2016$ & $\mathrm{Y}$ & $\mathrm{Y}$ & $\mathrm{Y}$ & bullfrog tadpoles, vulture $\mathrm{OH}$, blue jay, damsel flies \\
\hline 3 & $10 / 21 / 2016$ & $\mathrm{Y}$ & $\mathrm{Y}$ & $\mathrm{Y}$ & American bittern \\
\hline 4 & $10 / 21 / 2016$ & $\mathrm{Y}$ & $Y$ & $Y$ & \\
\hline
\end{tabular}

Table 2. Year 6 (2016) wetland monitoring report, showing observed animal species.

\section{Calculations:}

Environmental Design \& Research Landscape Architecture Planning, Environmental Services, Engineering and Surveying, P.C., 2016. "Wetland Mitigation Area Status Report".

\section{Limitations:}

Research was conducted more than five years ago by the landscape architect and not the LAF CSI research team. The research does not quantify observed wildlife, but rather lists the wildlife 
species that were observed during visits. The research also speculates at the potential existence of certain wildlife based on prevalence of habitat features, which can only provide a suggestion that such wildlife could potentially exist. Additionally, although monitoring each year for six years, the research team only had access to the final year of monitoring reports, limiting the degree to which we could understand the growth trajectory of the wetland over the entire six-year period.

- Generates an estimated 6.1 million $k$ Wh of electricity per year, enough electricity to power over 33,000 typical New York homes. This avoids 160,441 metric tons of carbon dioxide emissions annually.

Methods: Although information on the wind farm's actual energy output is not available publicly or from the owner, industry estimates project an annual output of $30-40 \%$ of a wind turbine's maximum capacity. With a 35\% capacity factor, a 2-MW turbine would produce $6,132,000 \mathrm{kWh}$ per year. In 2017, the average annual electricity consumption for a New York State residential utility customer was 6,864 kilowatt hours ( $\mathrm{kWh}$ ), an average of $572 \mathrm{kWh}$ per month. At this average annual electricity consumption, the 37-turbine wind farm can power an estimated 33,041 households annually.

The national weighted average carbon dioxide marginal emission rate for delivered electricity in 2017 was $1,559 \mathrm{lbs} \mathrm{CO}$ per MWh, which accounts for losses during transmission and distribution (EPA 2018).

From the EPA Website, 2019: "The Greenhouse Gas Equivalencies Calculator uses the AVoided Emissions and geneRation Tool (AVERT) U.S. national weighted average CO2 marginal emission rate to convert reductions of kilowatt-hours into avoided units of carbon dioxide emissions. AVERT calculates displaced emissions based on actual historical hourly patterns in generation by electric power plants within the contiguous 48 states and DC."

\section{Calculations:}

To calculate the number of households powered by the Hardscrabble wind farm at an average of $35 \%$ operation capacity:

$2 \mathrm{MW} \times 365$ days $\times 24$ hours $\times .35=6,132 \mathrm{MWh}=6,132,000 \mathrm{kWh}$ per year produced from a single wind turbine.

$6,132,000 \mathrm{kWh}$ per year $\times 37$ wind turbines $=\mathbf{2 2 6 , 8 8 4 , 0 0 0 ~} \mathrm{kWh}$ per year produced from the entire wind far,

226,884,000 kWh per year / 6,864 kWh average New York State residential household energy consumption per year $=33,041$ households powered per year by the entire wind farm. 
To calculate metric tons of $\mathrm{CO}_{2}$ avoided by the wind farm:

$1,559 \mathrm{lbs} \mathrm{CO} 2 / 226,884,000 \mathrm{kWh} \times(4.536 \times 10-4$ metric tons per lb $)=7.07 \times 10^{-}$ ${ }^{4}$ metric tons $\mathrm{CO}_{2}$ per $\mathrm{kWh}=160,441$ Metric Tons of $\mathrm{CO}^{2}$ avoided by the wind farm each year.

Sources:

U.S. Energy Information 2017 Average Monthly Bill- Residential (Data from forms ElA-861schedules 4A-D, EIA-861S and EIA-861U), National Wind Watch (https://www.wind-watch.org)

EPA (2018). "Quantifying the Multiple Benefits of Energy Efficiency and Renewable Energy: A Guide for State and Local Governments".

EPA (2018). Inventory of U.S. Greenhouse Gas Emissions and Sinks: 1990-2016. Chapter 3 (Energy), Tables 3-12, 3-13, and 3-14. Environmental Protection Agency, Washington, D.C. EPA \#430-R-18-003

FHWA (2018). Highway Statistics 2016. Office of Highway Policy Information, Federal Highway Administration. Table VM-1.

\section{Limitations:}

It is not possible to calculate specific energy benefits to the immediate geographic area impacted by the wind farm. The household energy bill data is an average for the entire state, and does not reflect the specific towns impacted by the wind farm. Additionally, the wind farm's output does not directly power a specific residential area, but rather serves as a more general power utility over a broader geographic region. 


\section{Social Benefits}

\section{A Note on Social Benefits}

In an attempt to assess the perceptions of the Hardscrabble Wind Farm during the planning process, we (as the CSI research team) planned and designed an interview/survey to administer to people who had played an instrumental role on the Town of Fairfield Planning Board. By applying for and receiving IRB exemption, we were limited in our approaches to recruit participants without seeking out personal contact information of individuals. Additionally those with whom we did talk about the survey, questioned what the point of such a survey was when the controversy was largely nonexistent 15 years after the project's completion. This may indicate that studies aimed at better understanding resistance, conflict, or controversy surrounding green energy landscapes such as wind farms are best conducted during or shortly after the planning period to most accurately and easily assess perceptions of those involved.

- Achieved low to moderate visual impact for landscape views with high scenic, historic, or community value. These views received a composite Visual Impact Assessment score of 2.01 on a scale of 1 (completely compatible) to 5 (strong visual contrast).

Methods: The landscape architect prepared a Visual Impact Assessment (VIA) for the original wind farm design which included 61 turbines. However, as a result of proposed turbine/layout changes which reduced the number of turbines to 37, the landscape architect prepared a Supplemental Visual Impact Assessment (SVIA). Public and agency comments on the original VIA suggested that views of the project during the growing season, and from additional specific viewpoints, should be simulated and evaluated. Supplemental photos were obtained from a variety of sites during August 2006, February 2008, and November 2008. From these, six viewpoints were selected for the development of supplemental simulations, along with one viewpoint from the original VIA.

To compare the original and revised design, a panel of three landscape architects was asked to evaluate the revised and supplemental simulations prepared for the SVIA. For the new viewpoints, the panel compared simulations of the currently proposed facilities (turbines and substation) with photos showing the existing view from each viewpoint and scored them on a scale from 1 (completely compatible) to -5 (strong visual contrast) based on a set of criteria (see appendix). $11 \times 17$-inch digital color prints were used for the evaluation of most of the photos. Proportionally-scaled larger plots were used for evaluation of the panoramic views.

Overall $100 \%$ of the evaluations of the 11 views revised to take into account the change in number and size of turbines fell under a visual contrast rating of 2.5, which is considered low to moderate with a majority falling under a score of 2 (low visual contrast). 
In comparing the 37-turbine Project to the original 61-turbine layout, the rating panel found that the newly-proposed project revisions resulted in a slight decrease in visual impact from most viewpoints. Supplemental simulations prepared from additional sensitive sites and/or during the growing season showed a range in visual contrast ratings from minimal (1.0) to moderate (3.0). The highest cumulative contrast rating (2.5) was received by a panoramic simulation where foreground and mid-ground turbines spanned the view and presented significant scale contrast. Supplemental growing season simulations generally received lower contrast ratings than simulations prepared during leaf-off conditions. A simulation of the proposed substation received low visual contrast ratings due to the small size of this project component, its color and scale compatibility with background vegetation, and/or its distance from available public vantage points. 

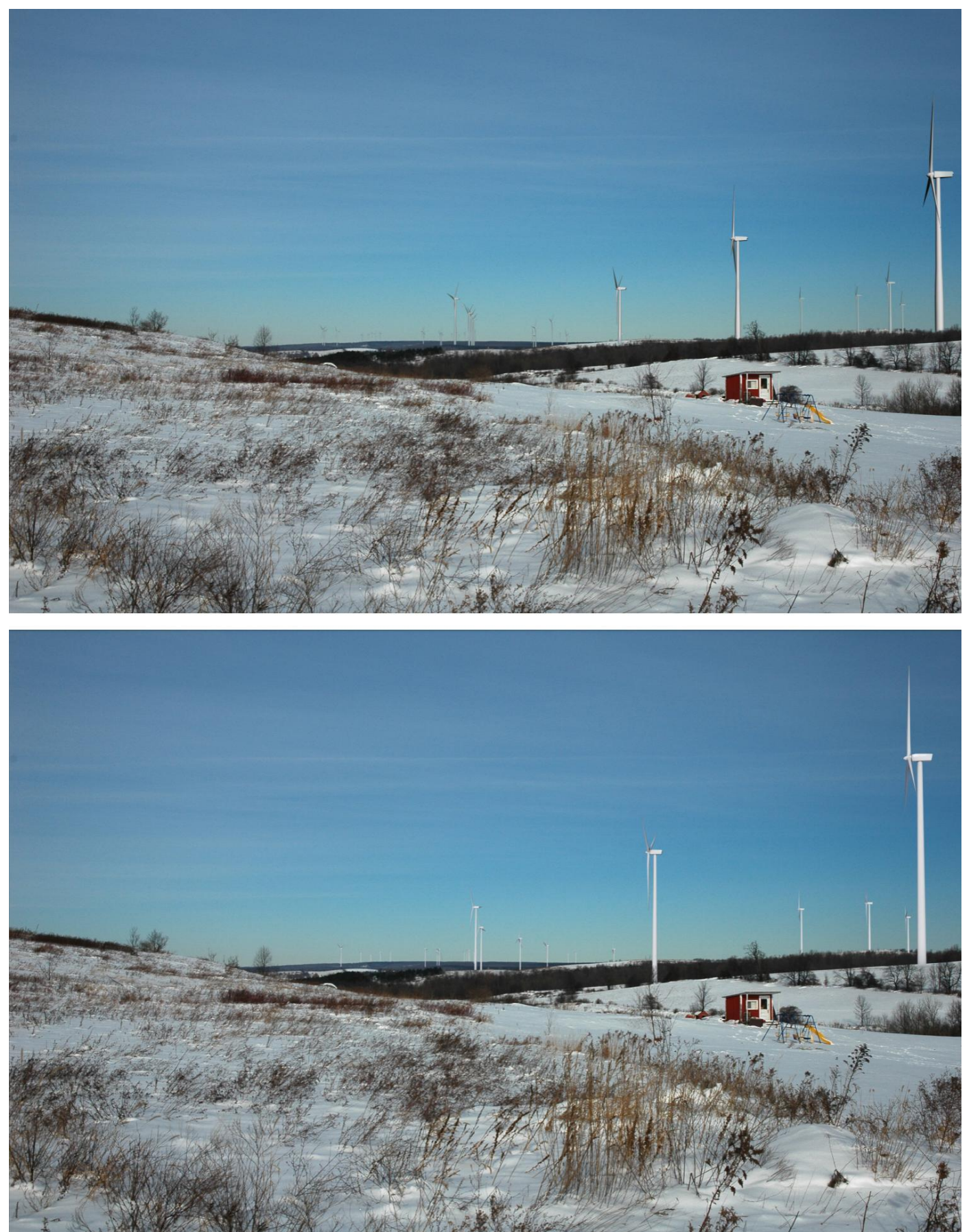

Figure 2. This shows the comparison between simulations created for the VIA (top) and the changes in turbine number and position for the SVIA (bottom) for viewpoint 148. 


\begin{tabular}{|c|c|c|c|c|c|}
\hline \multirow{2}{*}{ Viewpoint \# } & \multicolumn{3}{|c|}{ Individual Overall Scores $^{1}$} & \multirow{2}{*}{$\begin{array}{c}\text { Composite } \\
\text { Score }\end{array}$} & \multirow{2}{*}{$\begin{array}{c}\text { Change from } \\
\text { VIA } \\
\text { Composite } \\
\text { Score }\end{array}$} \\
\hline & LA 1 & LA 2 & LA 3 & & \\
\hline 25 & 2.25 & 1.25 & 1.25 & 1.58 & $-.05^{\star}$ \\
\hline 33 & 1.5 & 1.13 & 1.38 & 1.34 & +.05 \\
\hline 71 & 2.0 & 1.38 & 1.88 & 1.75 & -.04 \\
\hline 122 & 2.0 & 2.63 & 3.13 & 2.59 & -.29 \\
\hline 133 & 3.0 & 1.88 & 2.5 & 2.46 & -.12 \\
\hline 137 & 2.0 & 1.25 & 2.25 & 1.83 & -.34 \\
\hline 140 & 2.25 & 1.88 & 1.75 & 1.96 & -.04 \\
\hline 148 & 3.0 & 3.13 & 3.13 & 3.09 & +.01 \\
\hline 150 & 2.0 & 1.0 & 1.50 & 1.5 & -.08 \\
\hline 170 & 2.25 & 2.0 & 2.88 & 2.38 & +.04 \\
\hline 222 & 1.75 & 1.0 & 2.0 & 1.58 & 0 \\
\hline Average & 2.18 & 1.68 & 2.17 & 2.01 & -.07 \\
\hline
\end{tabular}

On a scale of 1 (completely compatible) to 5 (strong visual contrast).

* The composite score in the VIA was in error by .03. The correct composite VIA score for this viewpoint was 1.63.

Table 3. This table from the SVIA shows the panelists individual contrast ratings for $11 \mathrm{critical}$ project viewpoints. Ratings averaged by panelist and combined for a composite score for each view point, as well as an average composite score of 2.01

\section{Sources:}

Environmental Design \& Research, P.C., 2009. "Hardscrabble Wind Power Project Supplemental Visual Impact Assessment".

Environmental Design \& Research, P.C., 2006. "Visual Impact Assessment, Top Notch Wind Power Project".

Environmental Design \& Research Landscape Architecture Planning, Environmental Services, Engineering and Surveying, P.C., 2009. Final Environmental Impact Study for the Hardscrabble Wind Power Project.

\section{Limitations:}

The revised simulations did not include quantifiable differences in weather and atmospheric conditions. Views were intended to capture 'worst case' daytime and night time visibility based on maximum blade height and the height of turbine lights, as well as assess project visibility at sensitive sites outside the project area. Additionally, viewshed maps were created without taking into account the screening effects of existing vegetation or structures which resulted in a more conservative assessment of visibility impact. 
- Preserved views as anticipated, as demonstrated by pre-construction visual simulations achieving an average of $97.82 \%$ accuracy for turbine shaft height based on comparing to post-construction photographs.

Methods: Photographs of the visible wind turbines were taken in Summer 2019, with the photographer's positioning matching the original locations where the base photographs for visual simulations were captured in 2005 (winter) and 2006 (summer). The photographs and simulations were then compared to assess their similarity. A NIKON D50 digital SLR camera with a minimum resolution of 10 megapixels and the equivalent of a $50 \mathrm{~mm}$ lens setting was used to take the original photographs and a Nikon D7100 was used to take the comparison photos (2019). Global positioning system (GPS) equipment with sub-meter accuracy was used to position the photography setup to match the original simulation base photographs.

These photographs were prepared for digital comparison with the original photographic simulations. Turbine position was assessed primarily by delineating the height of the top of the turbine shaft relative to a constant reference point at the very bottom of the photograph. In total 11 out of 16 viewpoints were re-photographed, and 7 out of those 11 were assessed for accuracy.

Turbines were categorized into foreground, middleground, and background based on definitions outlined in Hoffman \& Palmer (1996). "Traditionally, distance in landscape views is divided into foreground, middleground, and background. These divisions are founded on the theory of space as applied to composition in painting and photography for the purpose of creating the allusion of three-dimensionally on flat, two-dimensional surfaces (Higuchi 1975).

\section{FOREGROUND}

The foreground is the nearest part of a view in which details of individual features are visible. The leaves, trunks, and branches are discernible as belonging to particular trees, and people are able to relate the size of each tree to their own height. The foreground may extend up to 1,500 feet from the observer.

\section{MIDDLEGROUND}

The middleground is that part of the view between the foreground and the background, usually between one-half to four miles. The outline of groups of trees is evident but surface detail is lost. It is possible to recognize different species by color and texture when similar trees are grouped.

\section{BACKGROUND}

The background is that part of a landscape composition which is furthest from the observer. This may be three to five miles. Details are lost; the influence of atmospheric perspective causes textures to be uniform, and colors are only visible as lighter or darker parts of the overall view.

\section{Analysis 1: Turbine Position}

In order to assess the position and height of the turbine shafts, an object mapping methodology from Downes \& Lange (2015) was used. In order to determine the accuracy of the positioning and scale of the simulated turbines, digital linework was overlaid on the simulated and actual 
views. A single line was drawn over the turbine shaft to illustrate the turbine's height. An example of this is shown below:
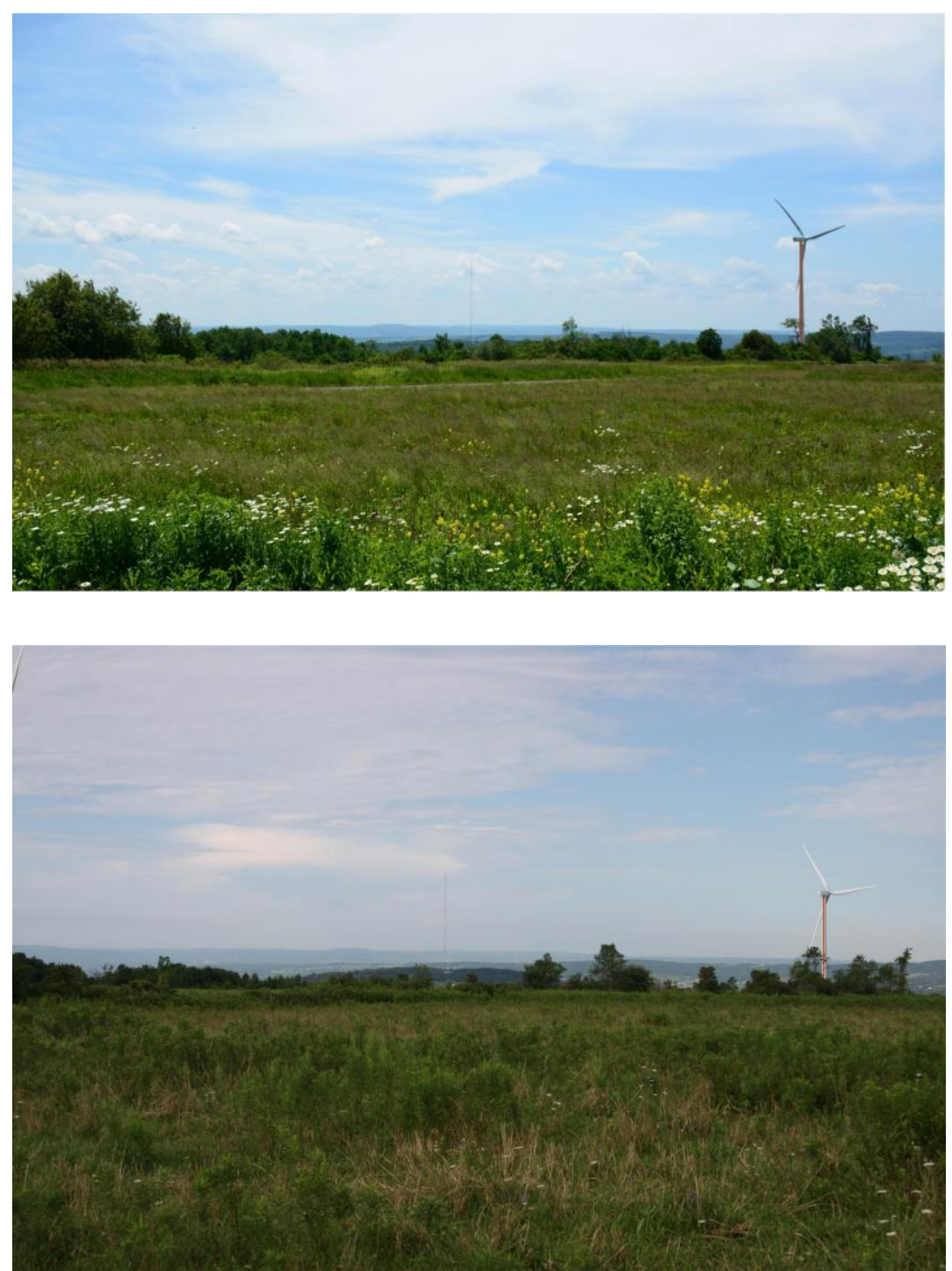

Figure 3. Red lines drawn over the photo (top) and the simulation (bottom) are compared in terms of height from the bottom of the artboard in Adobe Illustrator.

The overlay lines were extracted and layered to identify differences. The height differentiation from the bottom of the photograph are represented by dashed lines. 


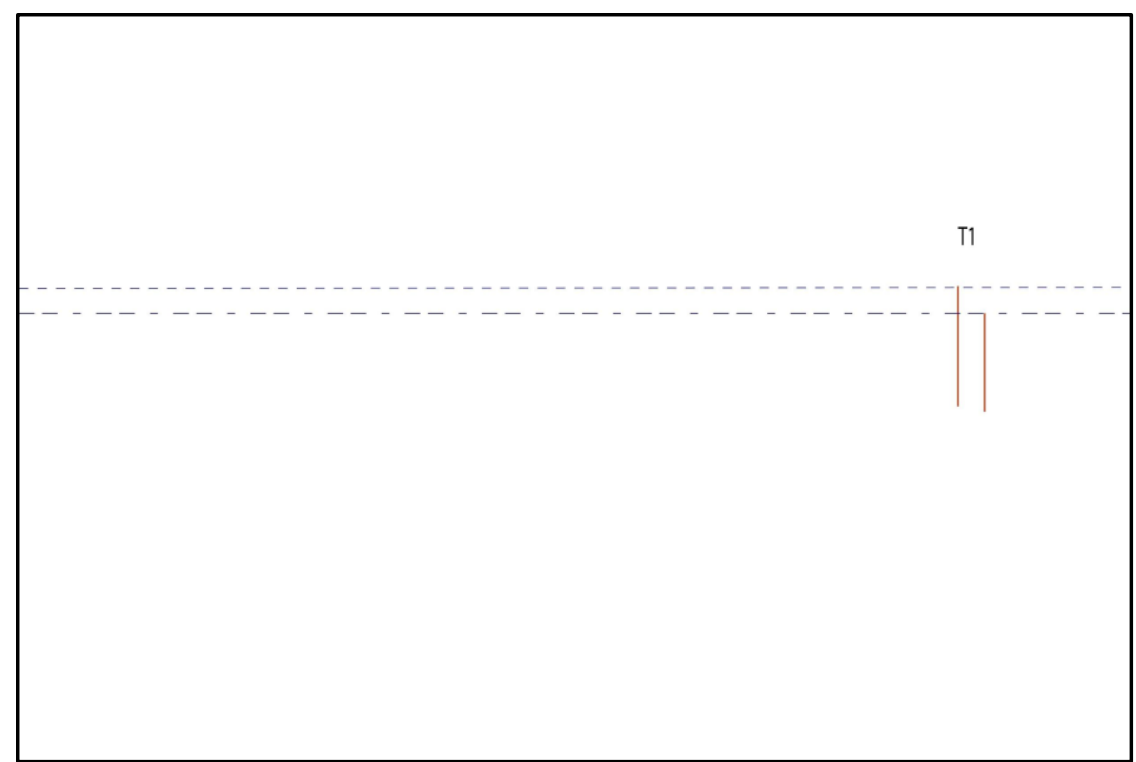

Figure 4. Lines drawn from the photo and the simulation side by side. The dashed lines represent the height difference.

The height difference between the simulated and constructed turbine was calculated as a percentage of the simulation height. That percentage was then subtracted from $100 \%$ to ascertain the \% accuracy for each turbine. 


\section{Results:}

SITE S2:

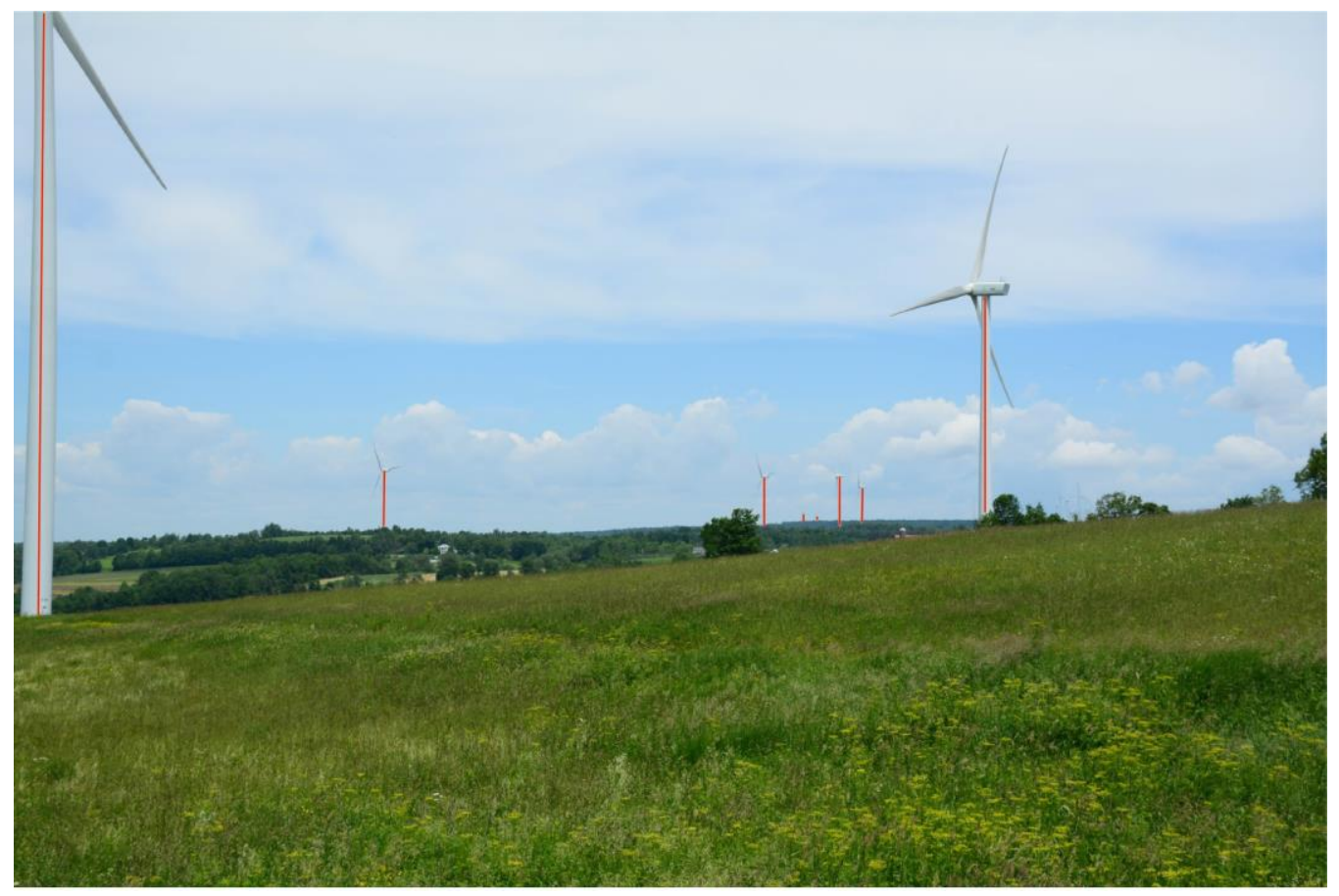

Figure 5. Actual turbines photographed on 6/27/19 at 12:18 PM, and the corresponding shaft delineations.

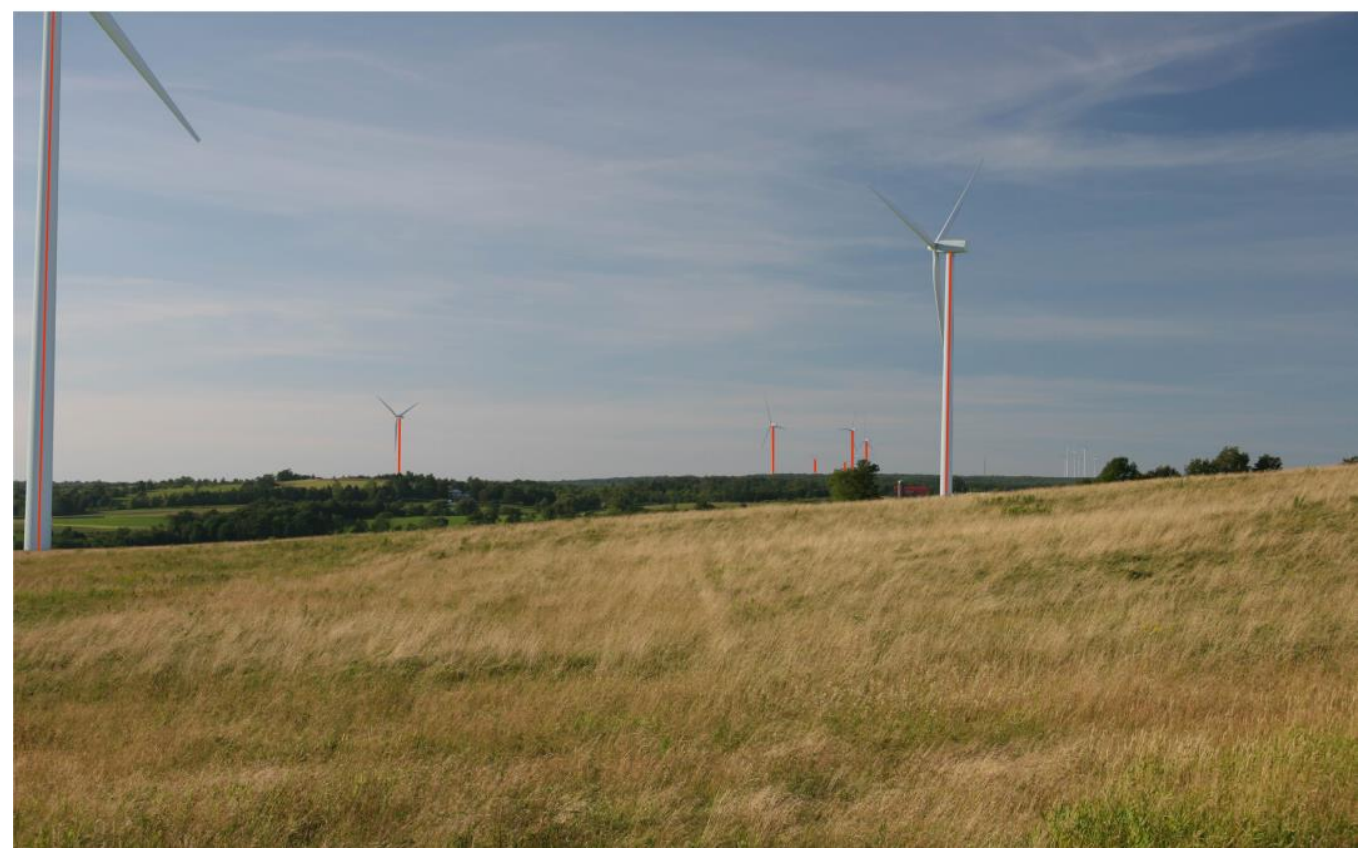

Figure 6. Simulated turbines positioned on a photo taken on 8/9/06 at 18:09 PM. 


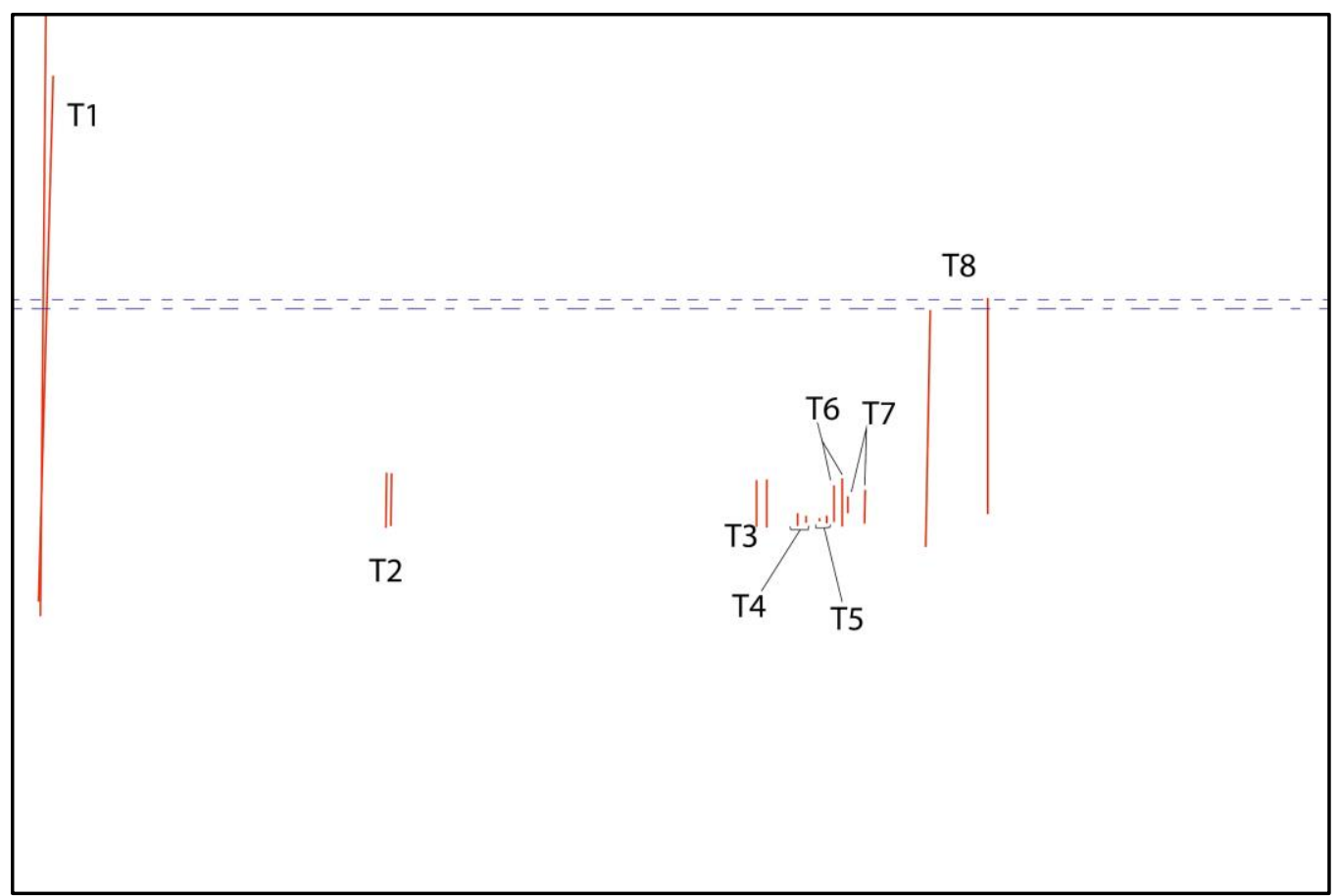

Figure 7. Outlines of the visible turbines. The dashed lines give one example of the difference in shaft height for turbine T8.

\begin{tabular}{|c|c|c|c|c|c|c|c|c|c|c|}
\hline \multicolumn{11}{|l|}{ SITE S2 } \\
\hline & & \multirow[b]{2}{*}{ Units } & \multirow[b]{2}{*}{ T1 } & \multirow[b]{2}{*}{ T2 } & \multirow[b]{2}{*}{ T3 } & \multicolumn{4}{|c|}{ Turbine or Cluster Number (L to R Across Photo) } & \multirow[b]{2}{*}{ T8 } \\
\hline & & & & & & T4 & T5 & T6 & $T 7$ & \\
\hline \multirow{4}{*}{ Height } & Simulation & & $* * 318.50$ & 459.31 & 451.67 & 415.50 & 412.63 & 446.00 & 434.00 & 638.50 \\
\hline & Photo & pixels & **302.50 & 460.00 & 452.50 & 412.56 & 410.00 & 453.67 & 441.00 & 651.50 \\
\hline & Difference & & 16.00 & 0.69 & 0.83 & 2.94 & 2.63 & 7.67 & 7.00 & 13.00 \\
\hline & Accuracy & $\%$ & 94.98 & 99.78 & 99.74 & 99.08 & 99.17 & 97.59 & 97.80 & 95.92 \\
\hline
\end{tabular}

** Indicates that the 'height' of the shaft was measured from its base to the bottom of the artboard as opposed to from the top of the shaft to the bottom of the art board. Calculations of Accuracy should reflect this estimation.

Table 4. Measured areas and heights of each of the turbines or clusters in both the simulation photo and the post-construction photo at site S2. It also shows the calculated percent accuracy of both parameters. The bottom row indicates whether the turbine is in the Foreground (FG), Middleground (MG), or Background (BG) of the photo. 


\section{SITE S13:}

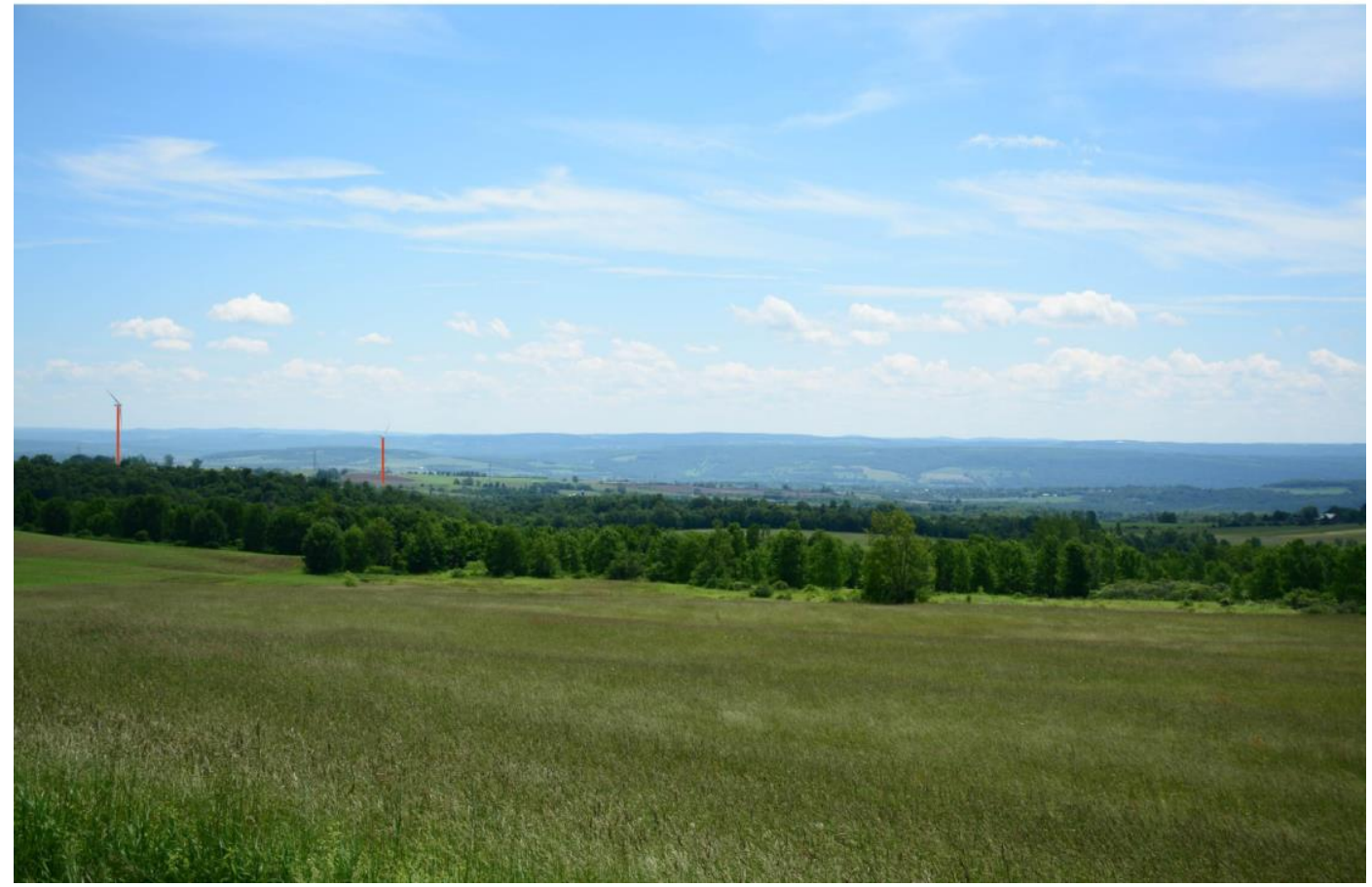

Figure 8. Actual turbines photographed on 6/27/19 at 13:40 PM, and the corresponding shaft delineations.

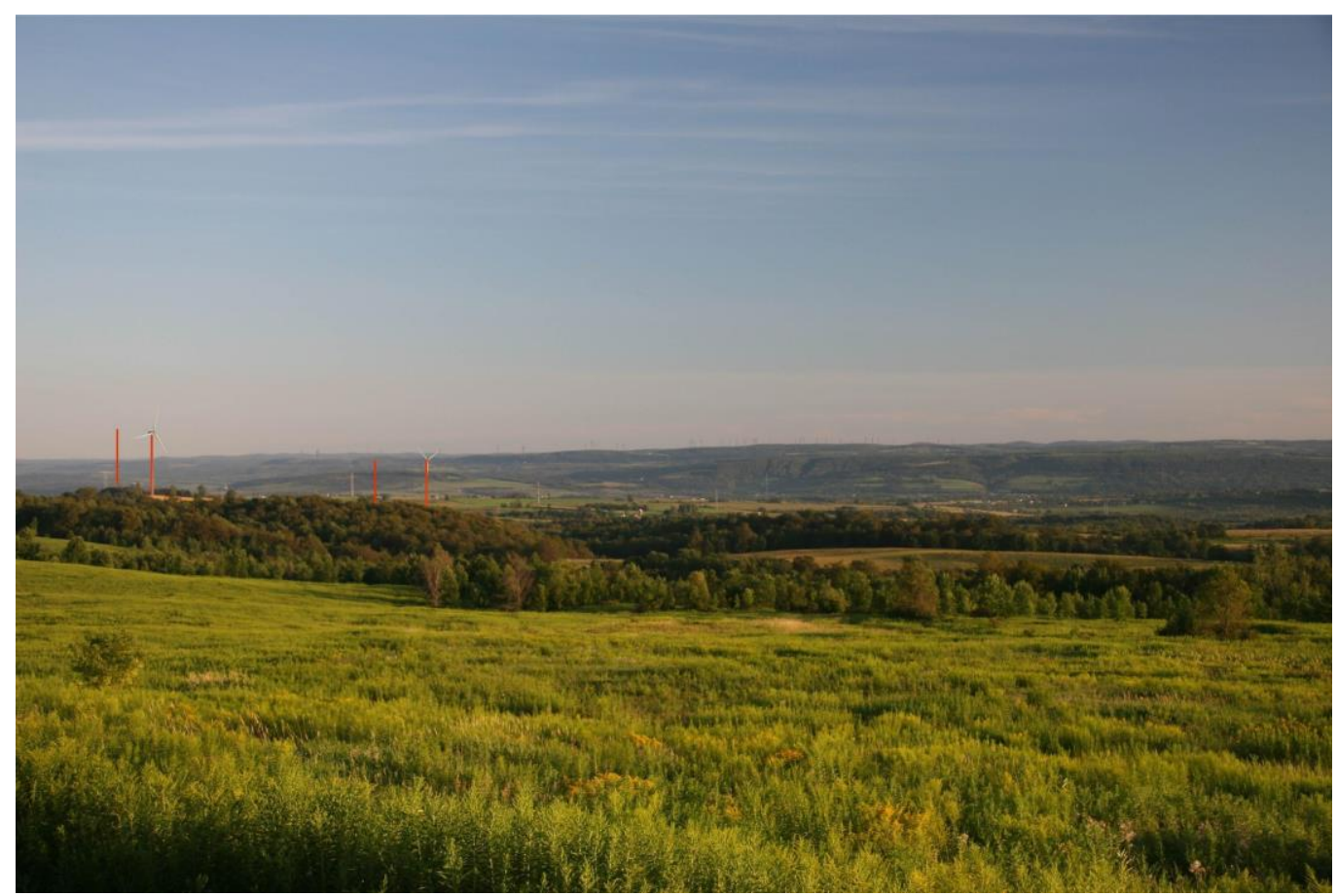

Figure 9. Simulated turbines positioned on a photo taken on 8/9/06 at 19:28 PM. 


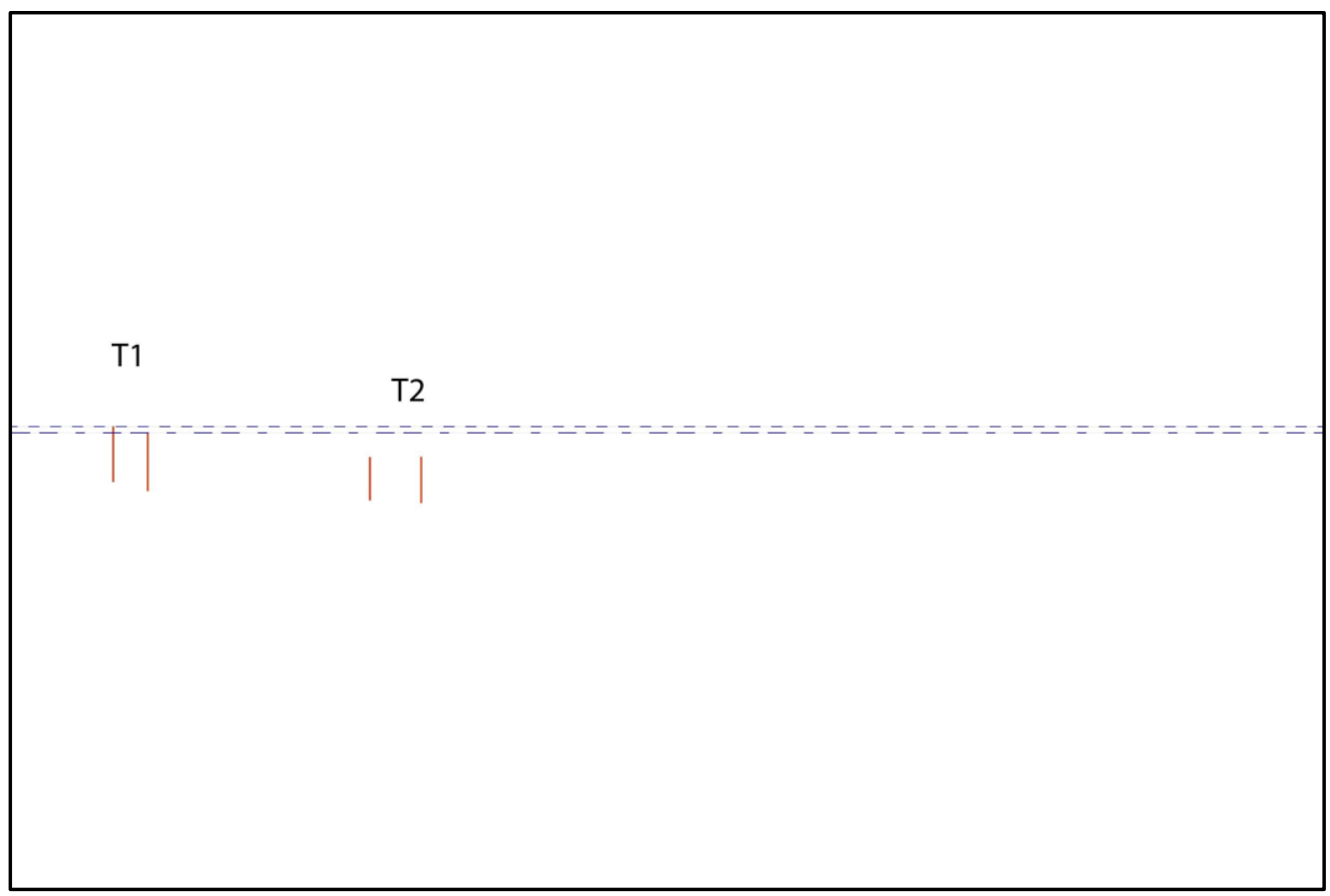

Figure 10. Outlines of the visible turbines and one cluster. The blue shading indicates the area of overlap, and the dashed lines give one example of the difference in shaft height for turbine T1.

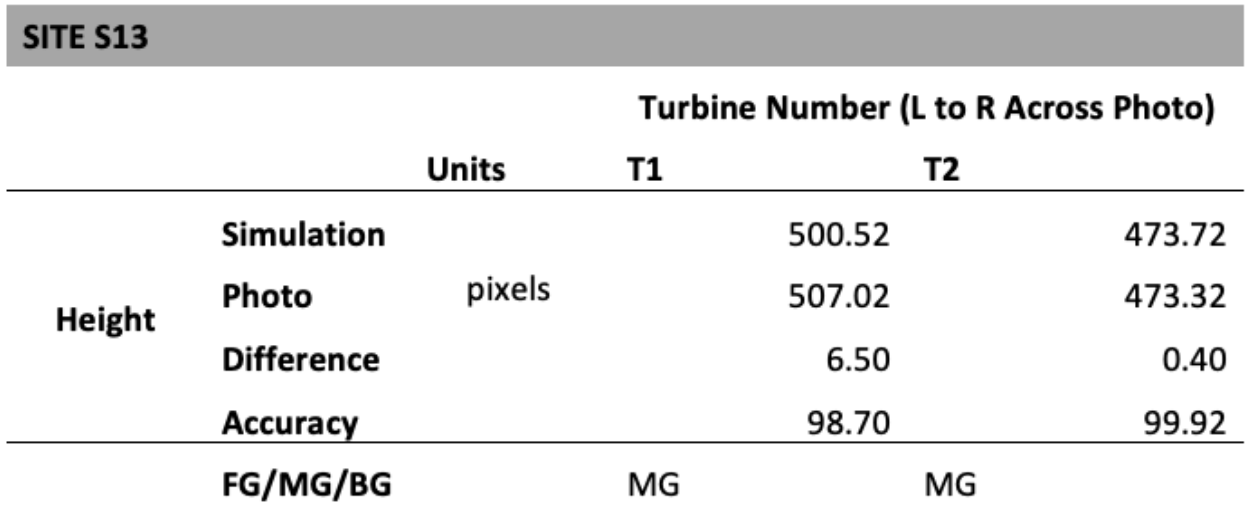

Table 5. Measured areas and heights of each of the turbines in both the simulation photo and the post-construction photo at site S13. It also shows the calculated percent accuracy of both parameters. The bottom row indicates whether the turbine is in the Foreground (FG), Middleground (MG), or Background (BG) of the photo. 


\section{SITE S21:}

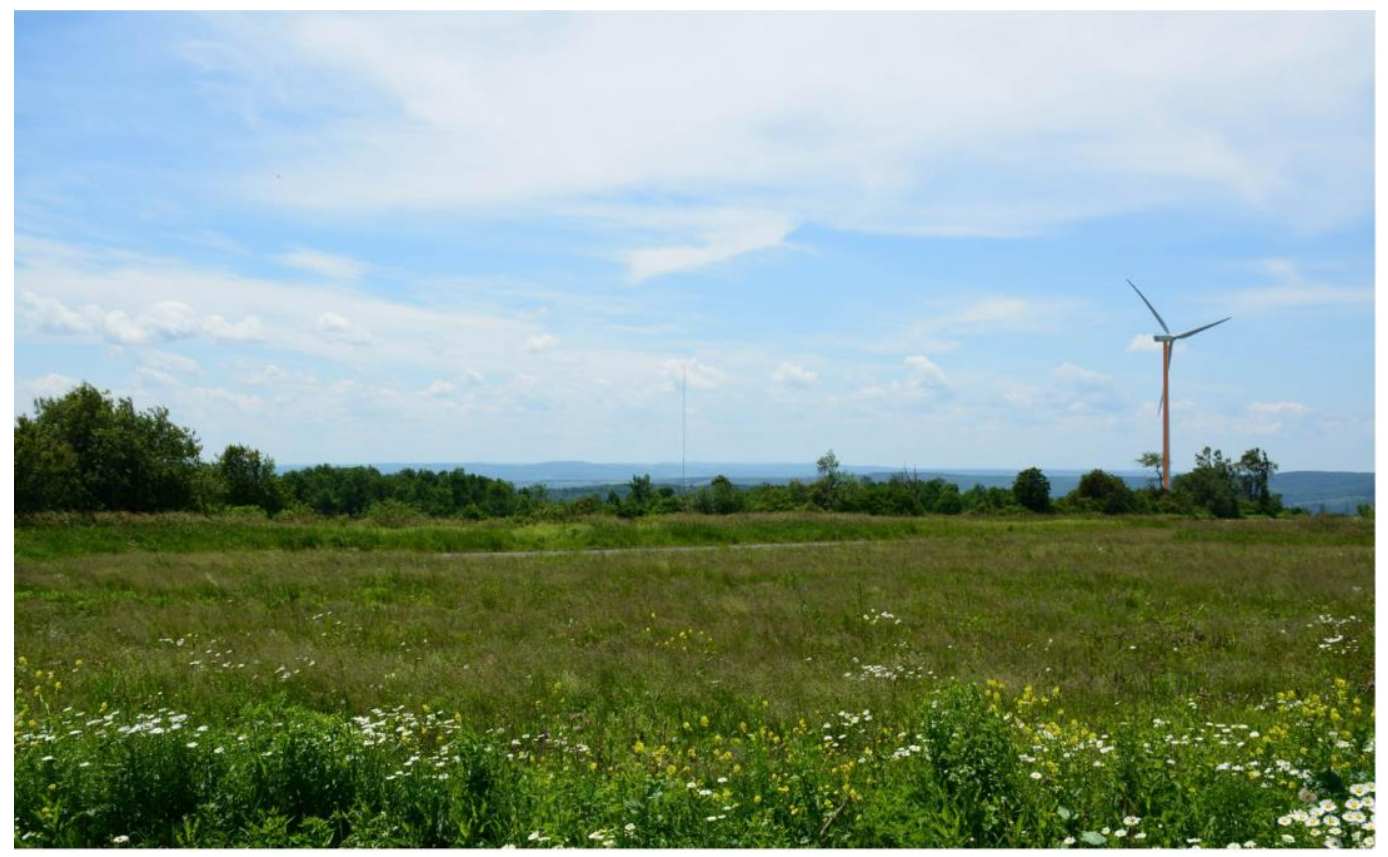

Figure 11. Actual turbine photographed on 6/27/19 at 13:26 PM, and the corresponding shaft delineation.

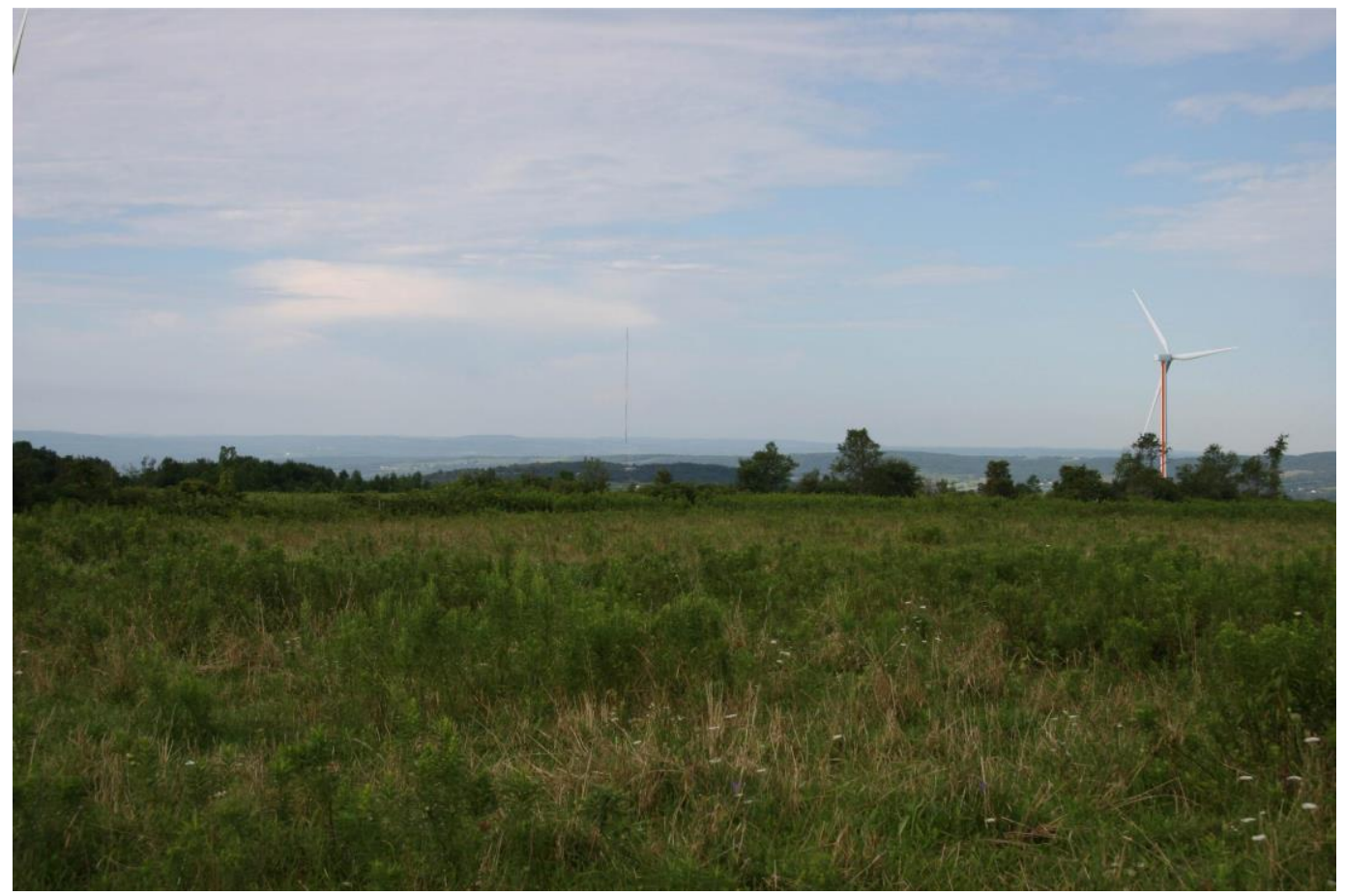

Figure 12. Simulated turbine positioned on a photo taken on 8/10/06 at 09:22 AM. 


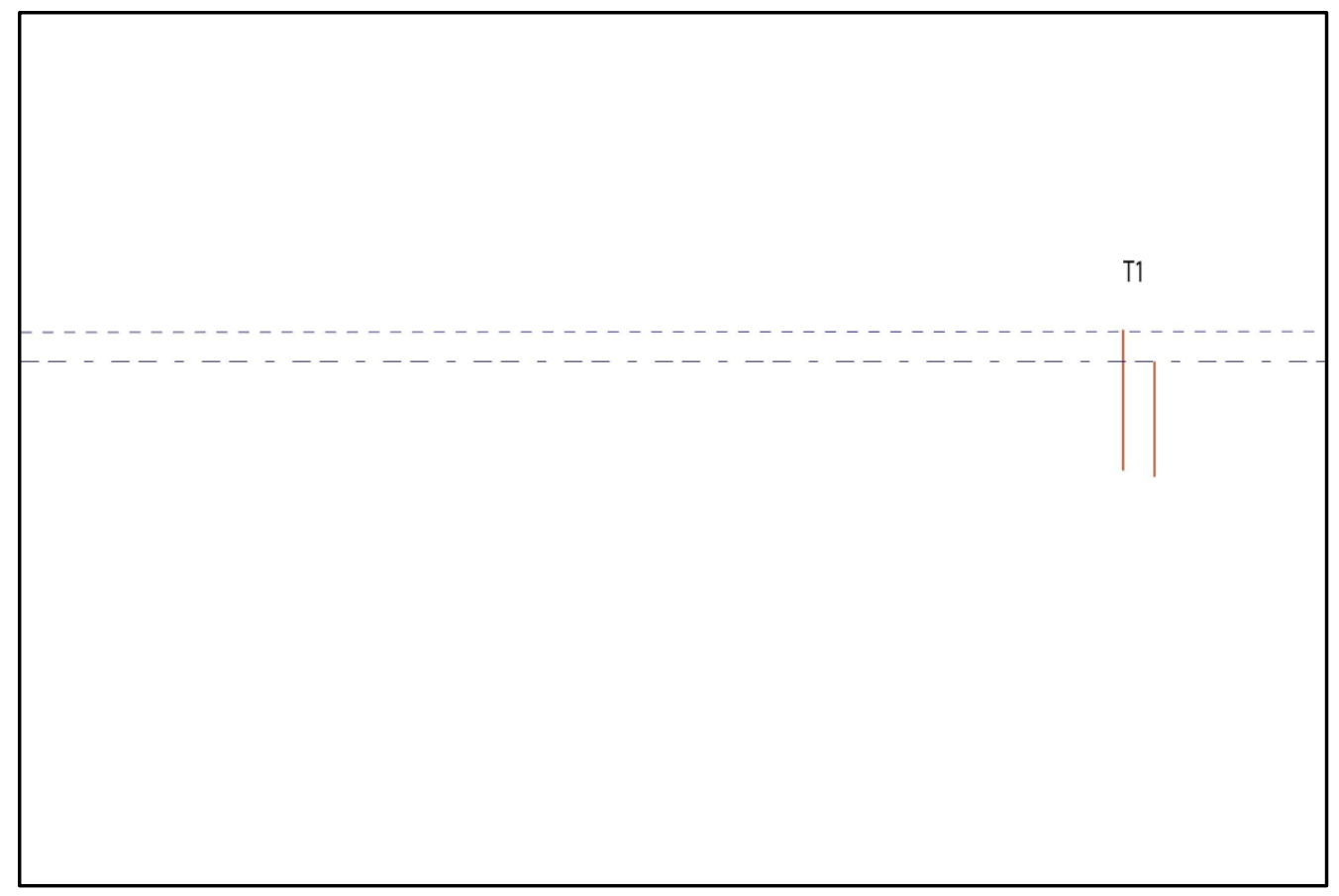

Figure 13. Outlines of the one visible turbine. The dashed lines give the difference in shaft height for turbine $\mathrm{T} 1$.

\section{SITE S21}

Turbine Number

Units T1

\begin{tabular}{rlrr}
\hline & Simulation & & 576.47 \\
Height & Photo & pixels & 611.52 \\
& Difference & & 35.05 \\
& Accuracy & $\%$ & 93.92 \\
\hline & FG/MG/BG & MG
\end{tabular}

Table 6. Measured height of the of the visible in both the simulation photo and the postconstruction photo at site S21. It also shows the calculated percent accuracy of height. The bottom row indicates whether the turbine is in the Foreground (FG), Middleground (MG), or Background $(B G)$ of the photo. 


\section{SITE VP133:}

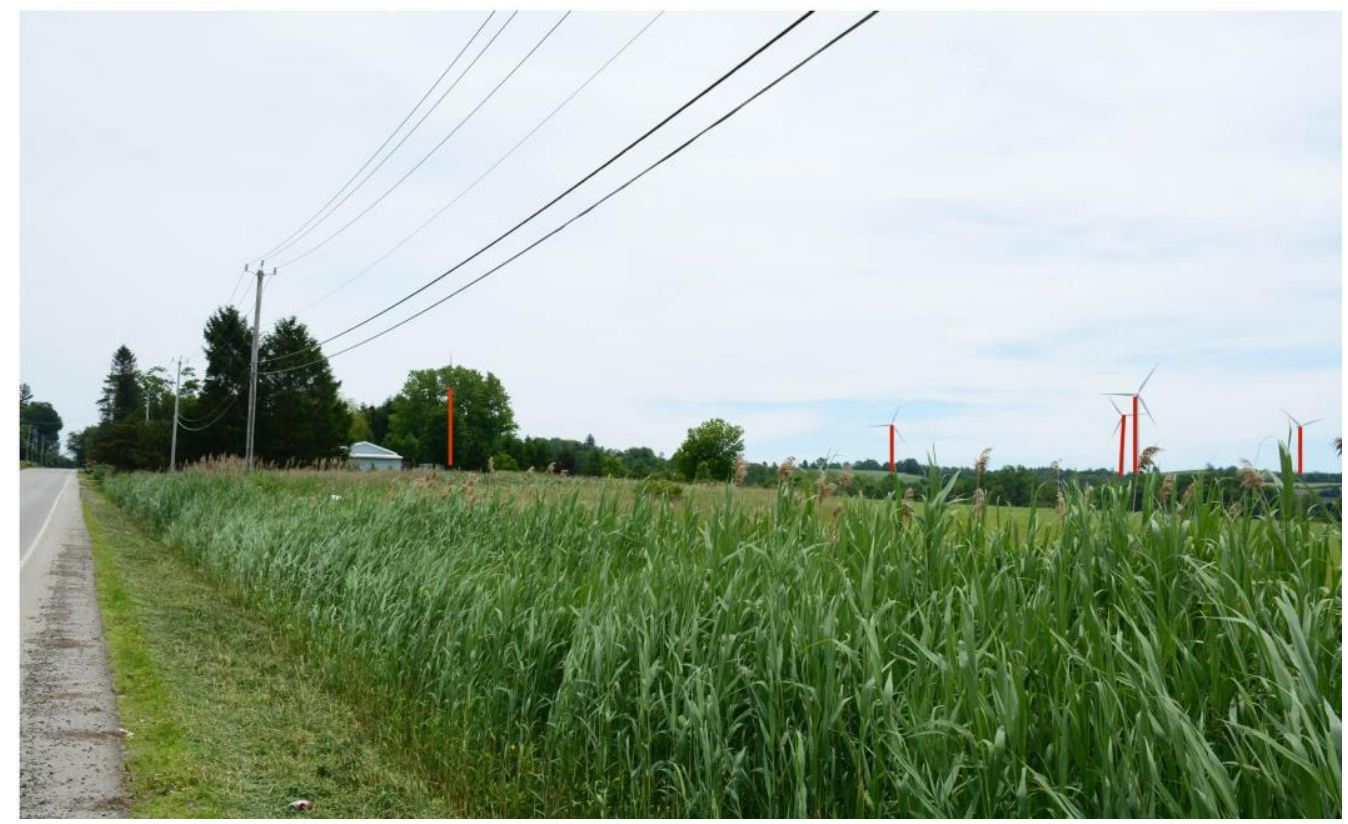

Figure 14. Actual turbines photographed on 6/27/19 at 11:41 AM, and the corresponding shaft delineations. Estimates were made for turbines whose shafts were obscured by vegetation.

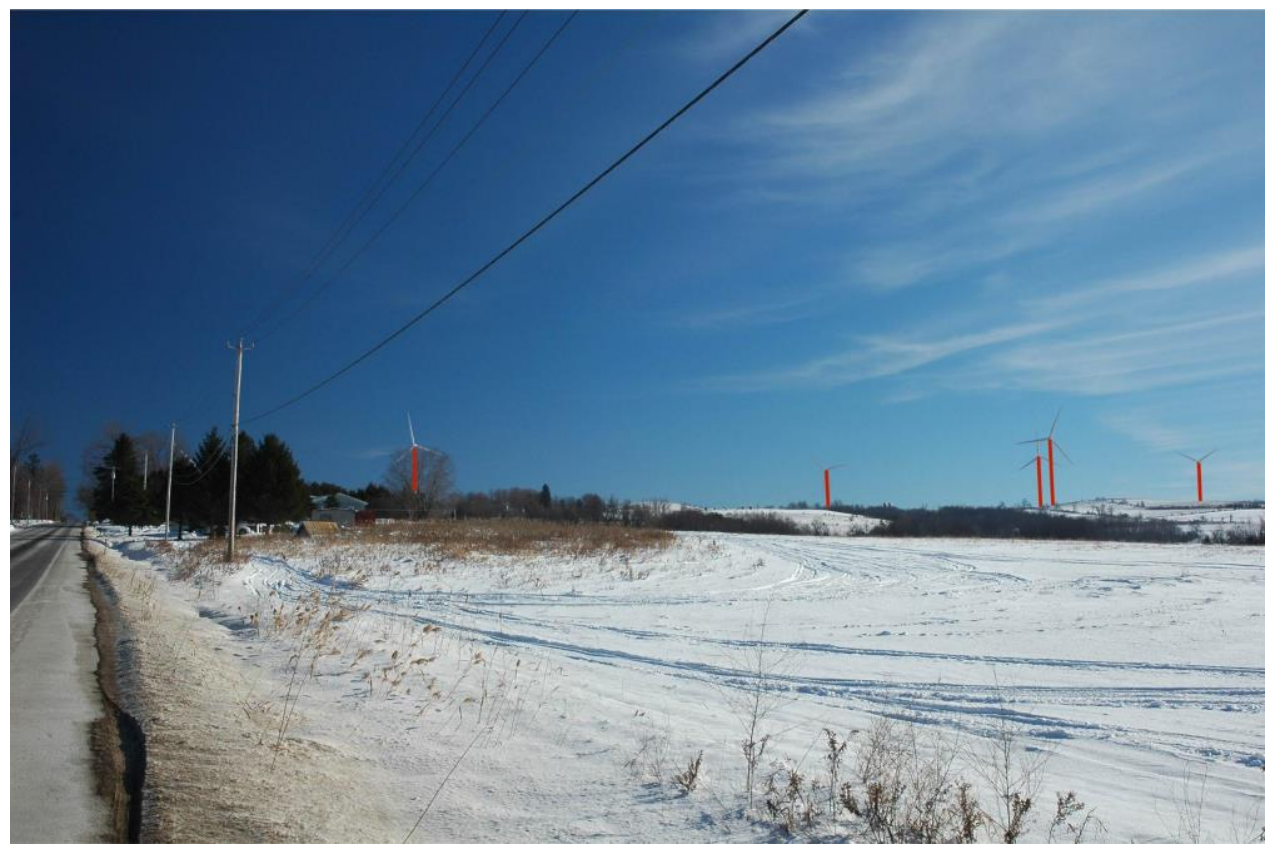

Figure 15. Simulated turbines positioned on a photo taken on 12/14/05 at 18:09 PM. 


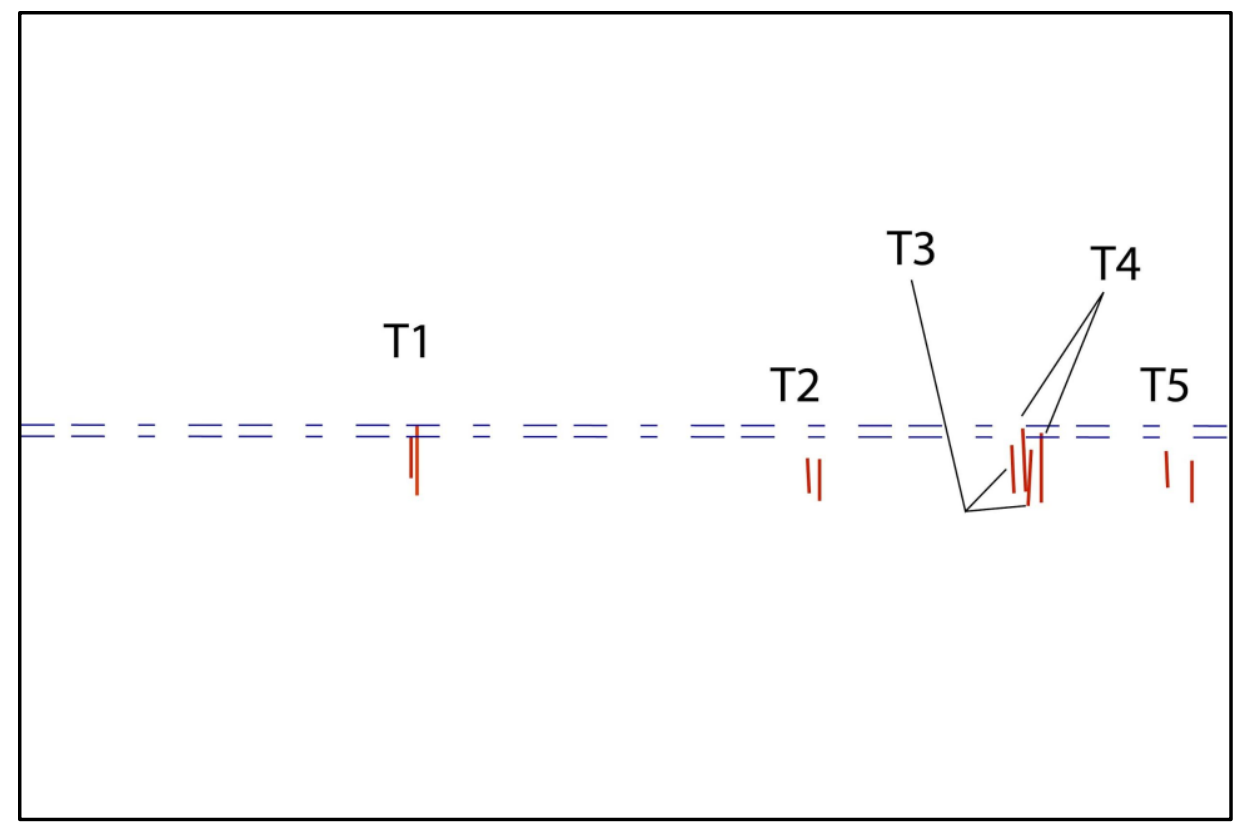

Figure 16. Outlines of the visible turbines. The dashed lines give one example of the difference in shaft height for turbine T1.

\begin{tabular}{|c|c|c|c|c|c|c|c|}
\hline \multicolumn{8}{|c|}{ SITE VP 133} \\
\hline & & \multirow[b]{2}{*}{ Units } & \multicolumn{5}{|c|}{ Turbine Number (L to R Across Photo) } \\
\hline & & & T1 & T2 & T3 & T4 & T5 \\
\hline \multirow{4}{*}{ Height } & Simulation & & 227.70 & 214.82 & 222.59 & 232.58 & 219.08 \\
\hline & Photo & pixels & $* * 234.64$ & 214.27 & 219.88 & 229.89 & 214.27 \\
\hline & Difference & & 6.94 & 0.55 & 2.71 & 2.69 & 4.81 \\
\hline & Accuracy & $\%$ & 96.95 & 99.74 & 98.78 & 98.84 & 97.80 \\
\hline & FG/MG/BG & & BG & BG & BG & BG & BG \\
\hline
\end{tabular}

** Indicates that the 'height' of the shaft was measured from its base to the bottom of the artboard as opposed to from the top of the shaft to the bottom of the art board. Calculations of Accuracy should reflect this estimation.

Table 7. Measured heights of each of the turbines in both the simulation photo and the postconstruction photo at site VP133. It also shows the calculated percent accuracy of height. The bottom row indicates whether the turbine is in the Foreground (FG), Middleground (MG), or Background (BG) of the photo. 


\section{SITE VP140:}

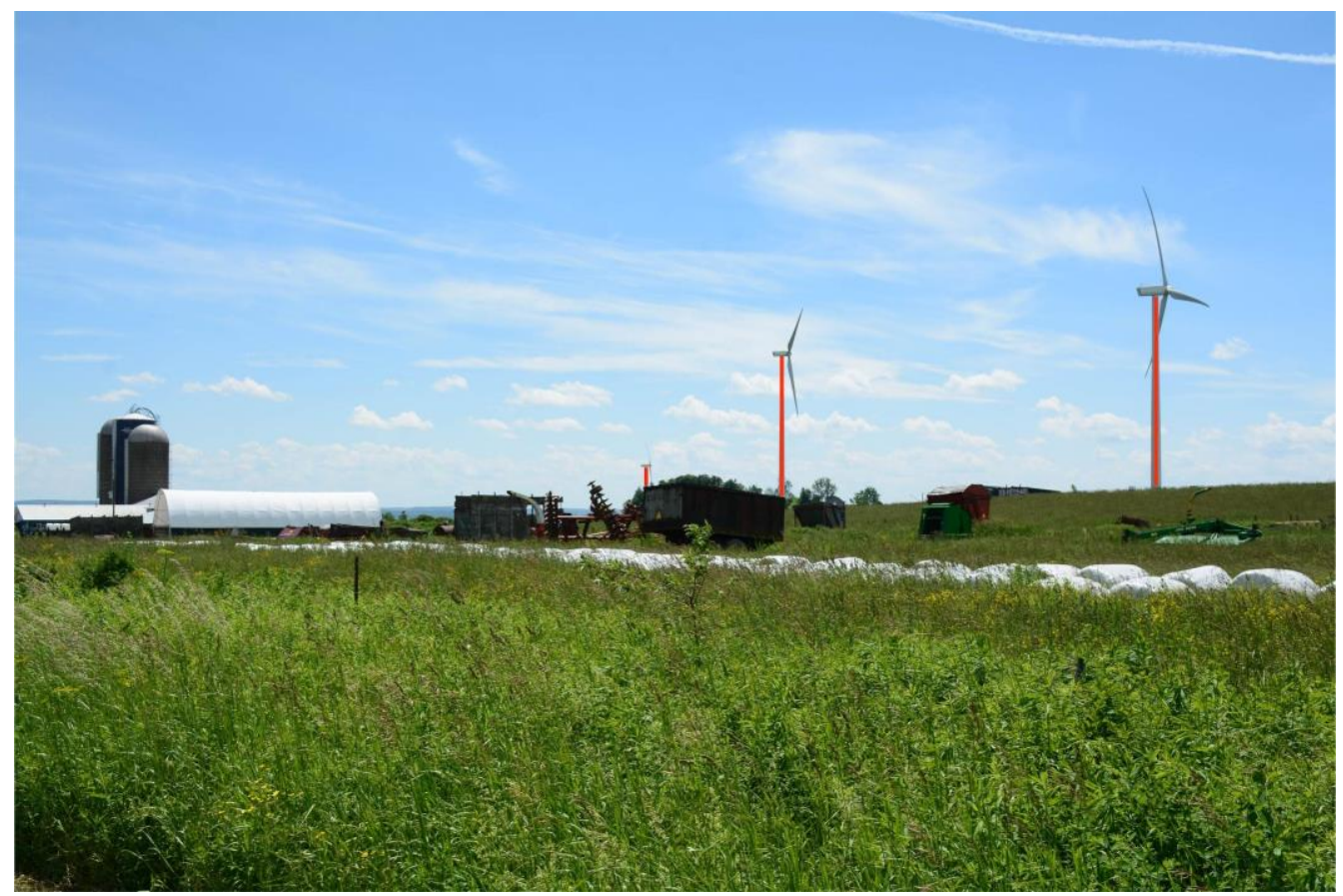

Figure 17. Actual turbines photographed on 6/27/19 at 14:04 PM, and the corresponding shaft delineations.

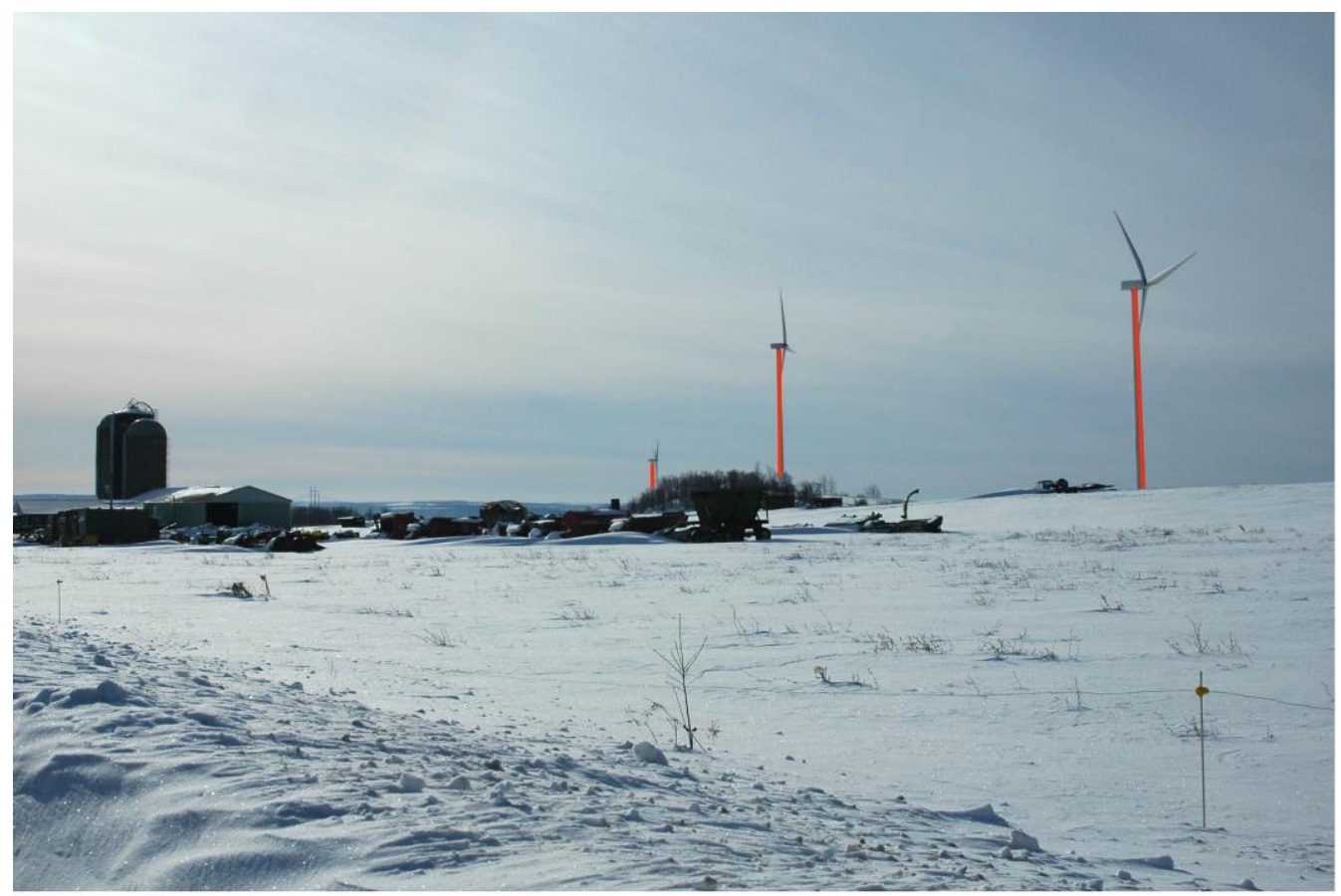

Figure 18. Simulated turbines positioned on a photo taken on 12/14/05 at 12:58 PM. 


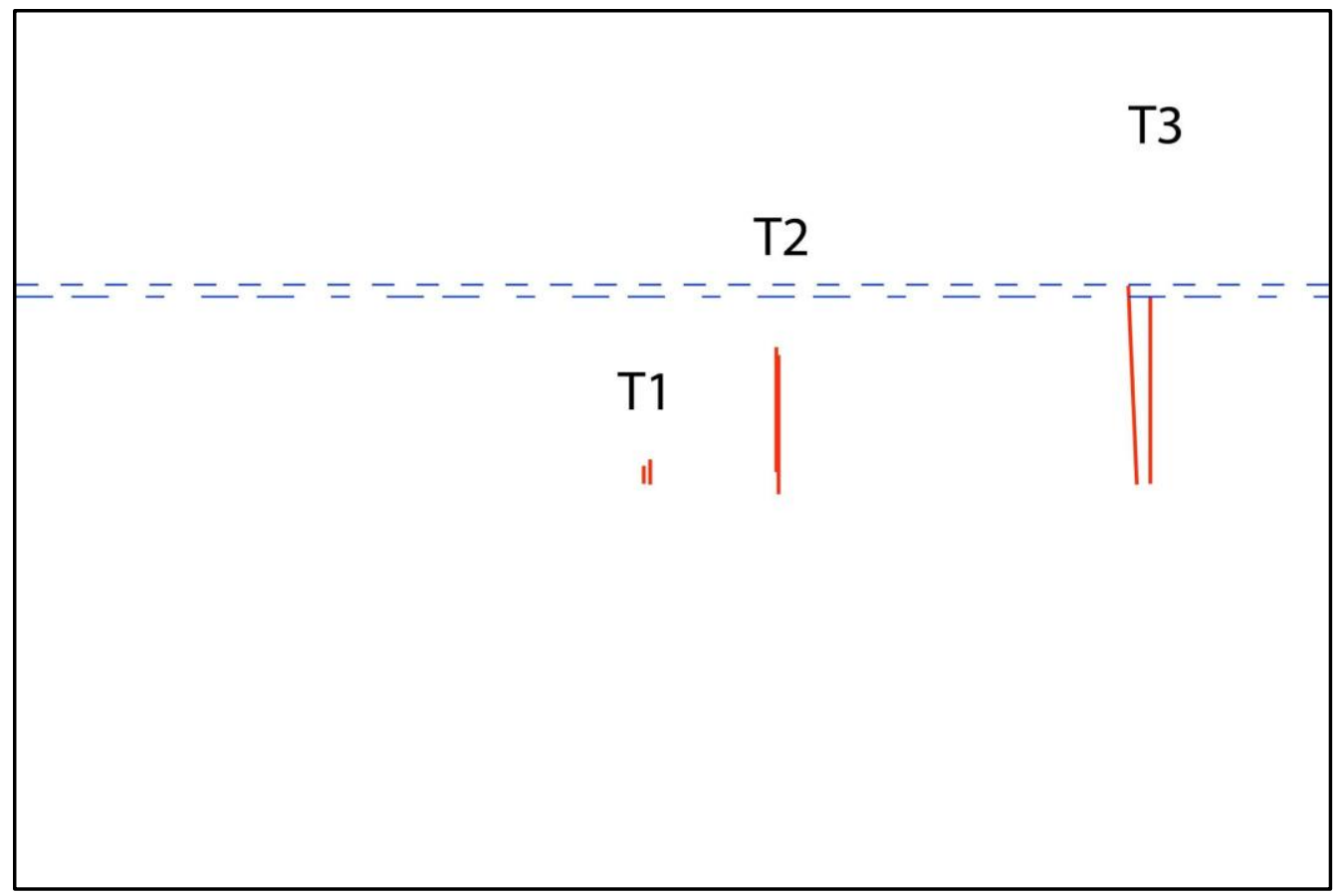

Figure 19. Outlines of the visible turbines. The dashed lines give one example of the difference in shaft height for turbine T3.

\section{SITE VP 140}

Turbine Number (L to R Across Photo)

\begin{tabular}{|c|c|c|c|c|c|}
\hline & & Units & T1 & T2 & T3 \\
\hline \multirow{4}{*}{ Height } & Simulatio & \multirow{3}{*}{ pixels } & 230.91 & 291.37 & 324.56 \\
\hline & Photo & & 227.44 & 287.03 & 318.71 \\
\hline & Difference & & 3.47 & 4.34 & 5.85 \\
\hline & Accuracy & $\%$ & 98.50 & 98.51 & 98.20 \\
\hline & \multicolumn{2}{|c|}{ FG/MG/BG } & BG & MG & MG \\
\hline
\end{tabular}

Table 8. Measured areas and heights of each of the turbines or clusters in both the simulation photo and the post-construction photo at site VP140. It also shows the calculated percent accuracy. The bottom row indicates whether the turbine is in the Foreground (FG), Middleground (MG), or Background (BG) of the photo. 


\section{SITE VP170:}

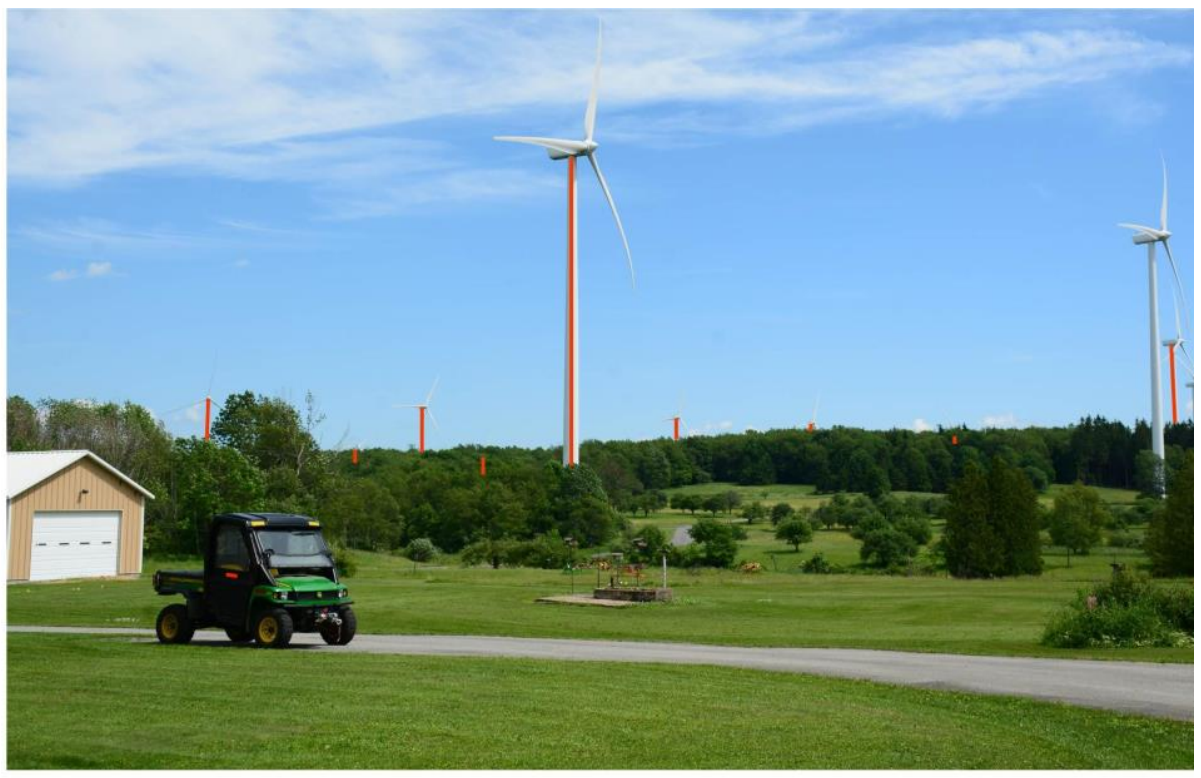

Figure 20. Actual turbines photographed on 6/27/19 at 15:13 PM, and the corresponding shaft delineations. Due to the difference in seasonality, and vegetation growth the shaft height was estimated for multiple turbines (See Table 9). Due to changes in the number and arrangement of turbines during the project planning process, two post construction turbines are not shown in the simulation image.

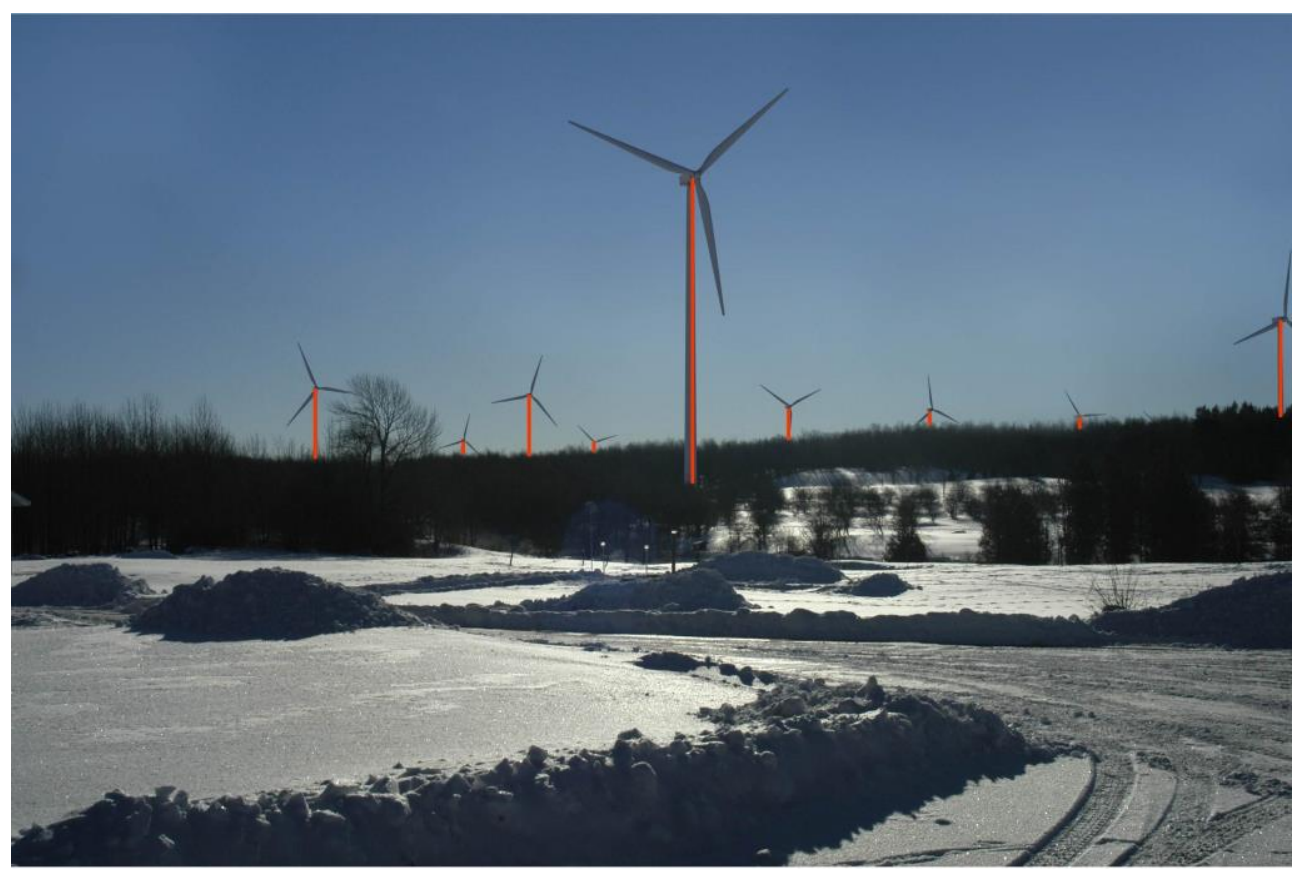

Figure 21. Simulated turbines positioned on a photo taken on 12/14/05 at 10:02 AM. 


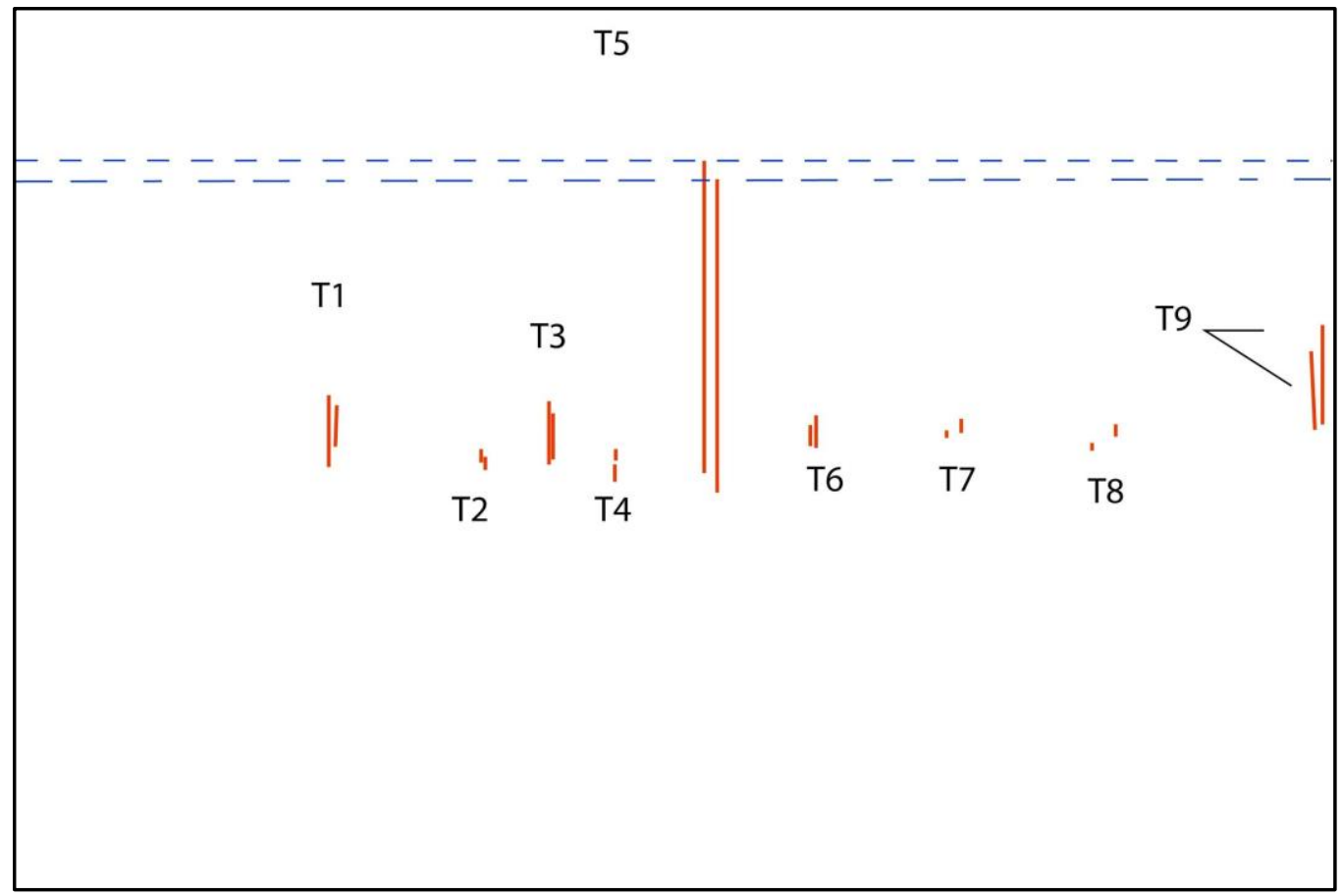

Figure 22. Outlines of the visible turbines. The dashed lines give one example of the difference in shaft height for turbine $\mathrm{T} 5$.

\begin{tabular}{|c|c|c|c|c|c|c|c|c|c|c|c|}
\hline \multicolumn{12}{|l|}{$\begin{array}{l}\text { SITE } \\
\text { VP170 }\end{array}$} \\
\hline & & \multirow[b]{2}{*}{ Units } & \multirow[b]{2}{*}{ T1 } & \multirow[b]{2}{*}{ T2 } & \multirow[b]{2}{*}{ T3 } & \multirow[b]{2}{*}{ T4 } & \multicolumn{4}{|c|}{ Turbine Number (L to R Across Photo) } & \multirow[b]{2}{*}{ T9 } \\
\hline & & & & & & & T5 & T6 & $\mathrm{T7}$ & T8 & \\
\hline \multirow{5}{*}{ Height } & Simulation & & 270.23 & 240.64 & 265.83 & 240.64 & 388.54 & 259.08 & 257.2 & 254.22 & 308.67 \\
\hline & Photo & pixels & 264.65 & 236.4 & 260.18 & $* * 232.31$ & 398.68 & 253.83 & 250.87 & $* * 243.98$ & 294.23 \\
\hline & Difference & & 5.58 & 4.24 & 5.65 & 8.33 & 10.14 & 5.25 & 6.33 & 10.24 & 14.44 \\
\hline & Accuracy & $\%$ & 97.94 & 98.24 & 97.87 & 96.54 & 97.39 & 97.97 & 97.54 & 95.97 & 95.32 \\
\hline & FG/MG/BG & & BG & BG & BG & BG & MG & BG & BG & BG & MG \\
\hline
\end{tabular}

Table 9. Measured heights of each of the turbines in both the simulation photo and the postconstruction photo at site VP170. It also shows the calculated percent accuracy of the height. The bottom row indicates whether the turbine is in the Foreground (FG), Middleground (MG), or Background (BG) of the photo. 


\section{SITE VP148:}

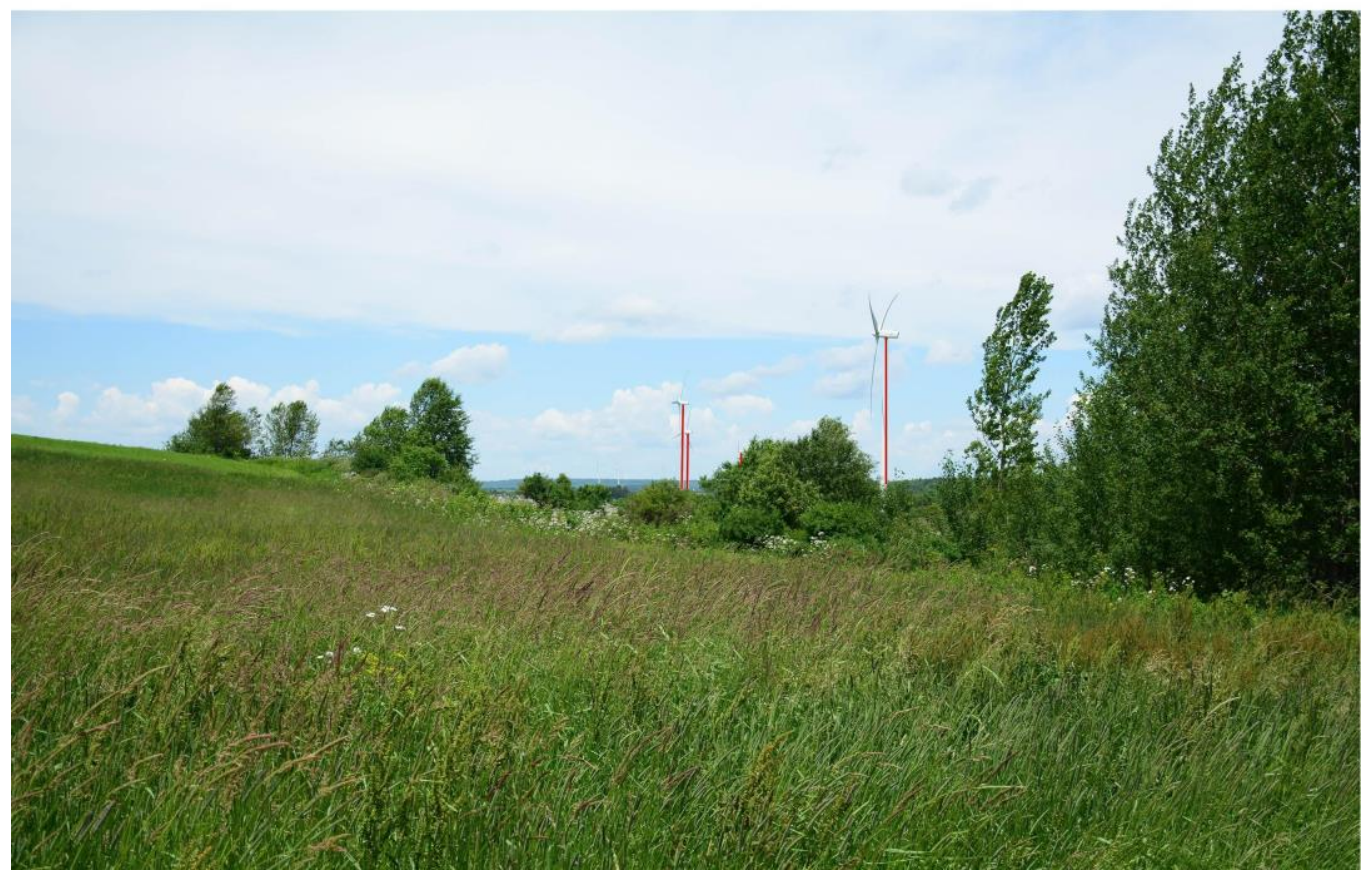

Figure 23. Actual turbines photographed on 6/27/19 at 13:51 PM, and the corresponding shaft delineations. At this site mature vegetation obstructed multiple turbines that were included in the original view. These were not included in the assessment.

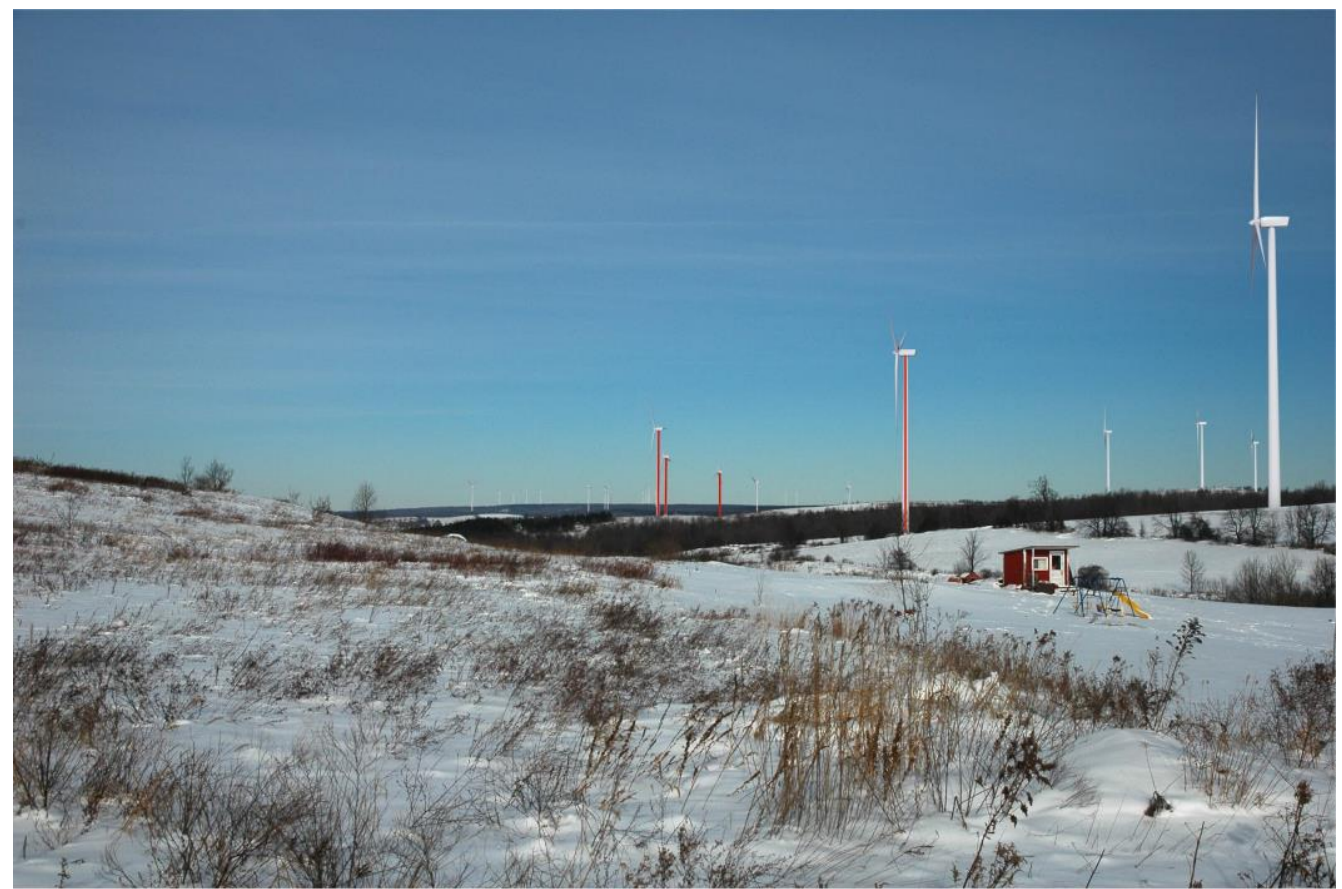

Figure 24. Simulated turbines positioned on a photo taken on 8/9/06 at 18:09 PM. Turbines that were not assessed have no red outlining. 


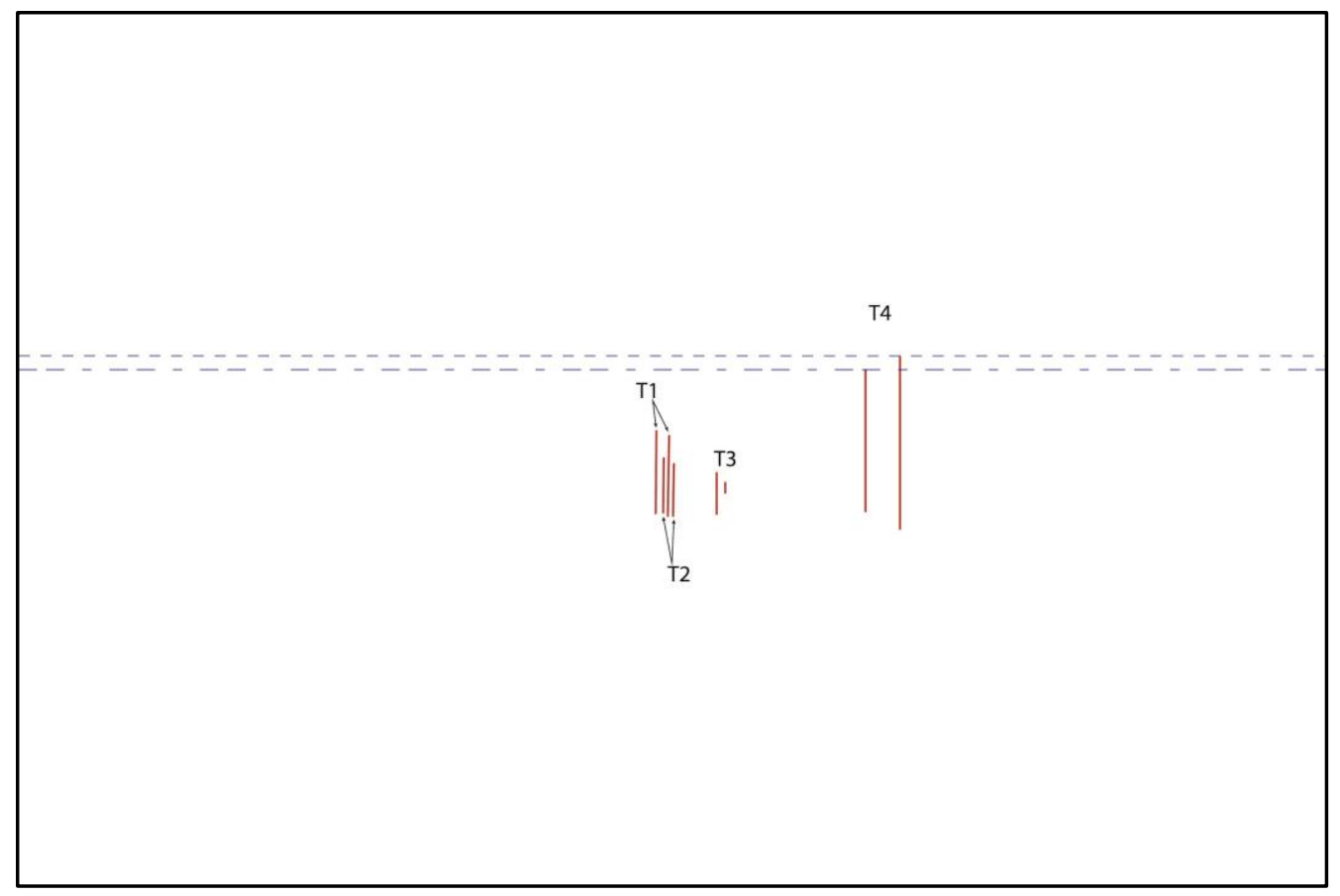

Figure 25. Outlines of the visible turbines. The dashed lines give one example of the difference in shaft height for turbine T8.

\begin{tabular}{|c|c|c|c|c|c|c|}
\hline \multicolumn{7}{|c|}{ SITE VP 148} \\
\hline & & \multirow[b]{2}{*}{ Units } & \multicolumn{4}{|c|}{ Turbine or Cluster Number (L to R Across Photo) } \\
\hline & & & T1 & T2 & T3 & T4 \\
\hline \multirow{4}{*}{ Height } & Simulation & \multirow{3}{*}{ pixels } & 501.47 & 471.51 & 455.06 & 583.41 \\
\hline & Photo & & 495.97 & 464.95 & 444.38 & 568.16 \\
\hline & Difference & & 5.50 & 6.56 & 10.68 & 15.25 \\
\hline & Accuracy & $\%$ & 98.90 & 98.61 & 97.65 & 97.39 \\
\hline & FG/MG/BG & & MG & MG & BG & MG \\
\hline
\end{tabular}

Table 10. Measured areas and heights of each of the turbines in both the simulation photo and the post-construction photo at site VP148. It also shows the calculated percent accuracy of the height. The bottom row indicates whether the turbine is in the Foreground (FG), Middleground (MG), or Background (BG) of the photo. 


\section{Calculations:}

Sum of all turbine pixel accuracy percentages / number of compared turbines $=$ average turbine \% pixel accuracy of shaft height visual simulations

$98.70+99.92+94.98+95.92+99.78+99.74+99.08+99.17+97.59+97.80+93.92+$ $96.95+98.78+98.78+98.84+97.80+98.51+98.20+98.50+98.90+98.61+97.39+$ $97.65+97.39+95.32+97.94+98.24+97.87+96.54+97.97+97.54+95.97=\mathbf{3 1 3 0 . 2 9}$

$3130.29 / 32=97.82 \%$ average turbine $\%$ pixel accuracy of shaft height visual simulations

\begin{tabular}{|c|c|c|c|}
\hline \multicolumn{4}{|c|}{ Turbine Shaft Height Accuracy } \\
\hline & ViewPoint & $\begin{array}{c}\text { Turbine or } \\
\text { Cluster \# }\end{array}$ & \% Accuracy \\
\hline Foreground & S2 & $\mathrm{T} 1$ & 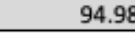 \\
\hline \multirow{11}{*}{ Middleground } & S2 & T8 & 95.92 \\
\hline & S13 & T1 & 98.70 \\
\hline & S13 & $\mathrm{T} 2$ & 99.92 \\
\hline & S21 & $\mathrm{T} 1$ & 93.92 \\
\hline & VP140 & $\mathrm{T} 2$ & 98.51 \\
\hline & VP140 & $\mathrm{T} 3$ & 98.20 \\
\hline & VP170 & T5 & 97.39 \\
\hline & VP170 & T9 & 95.32 \\
\hline & VP148 & T1 & 98.90 \\
\hline & VP148 & $\mathrm{T} 2$ & 98.61 \\
\hline & VP148 & $\mathrm{T} 4$ & 97.39 \\
\hline \multirow{2}{*}{$\begin{array}{c}\text { Average } \\
\text { Middleground }\end{array}$} & & & \\
\hline & & & 97.53 \\
\hline \multirow{20}{*}{ Background } & S2 & $\mathrm{T} 2$ & 99.78 \\
\hline & S2 & T3 & 99.74 \\
\hline & S2 & T4 & 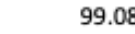 \\
\hline & S2 & T5 & 99.17 \\
\hline & S2 & T6 & 97.59 \\
\hline & S2 & 77 & 97.80 \\
\hline & VP133 & $\mathrm{T} 1$ & 96.95 \\
\hline & VP133 & $\mathrm{T} 2$ & 98.78 \\
\hline & VP133 & T3 & 98.78 \\
\hline & VP133 & T4 & 98.84 \\
\hline & VP133 & T5 & 97.80 \\
\hline & VP140 & T1 & 98.50 \\
\hline & VP170 & T1 & 97.94 \\
\hline & VP170 & $\mathrm{T} 2$ & 98.26 \\
\hline & VP170 & T3 & 97.87 \\
\hline & VP170 & T4 & 96.54 \\
\hline & VP170 & T6 & 97.97 \\
\hline & VP170 & $\pi$ & 97.54 \\
\hline & VP170 & T8 & 95.97 \\
\hline & VP148 & $\mathrm{T} 3$ & 97.65 \\
\hline \multicolumn{3}{|l|}{$\begin{array}{l}\text { Average } \\
\text { Background }\end{array}$} & 98.13 \\
\hline \multicolumn{3}{|l|}{$\begin{array}{l}\text { TOTAL } \\
\text { AVERAGE }\end{array}$} & 97.82 \\
\hline
\end{tabular}

Table 11. Height differences between simulated and constructed turbines, showing a total average accuracy of $97.82 \%$. 


\section{Sources:}

Hoffman, R. and Palmer, J. (1996). Visual Quality of Forest Vistas: A Literature Review. SUNY College of Environmental Science and Forestry.

Downes, M. and Lange, E. (2015). What you see is not always what you get: A qualitative, comparative analysis of ex ante visualizations with ex post photography of landscape and architectural projects, Landscape and Urban Planning, 142, 136-146, https://doi.org/10.1016/i.landurbplan.2014.06.002.

Katukam, R. 2015. Image Comparison Methods \& Tools: A Review. 1st National Conference on Emerging Trends in Information Technology [ETIT], 28th -29th December 2015, 35-42.

\section{Limitations:}

Some problems occurred when comparing turbines in the extreme foreground or background. When outlining the shafts of turbines in the background of the images, some clusters of turbines were omitted due to high chance of error that could occur during image comparison of such small pixel areas. Additionally, only one turbine was categorized as foreground. Of the remaining turbines, the average middleground turbine was $97.53 \%$ accurate, which was .6\% lower than the average background turbine which had a $98.13 \%$ accuracy. There were too few foreground turbines to make any preliminary assessment on difference in accuracy.

Not all viewpoints could be photographed during data collection for the case study due to a number of reasons. The primary reason was lack of time, as the firm liaison could only accompany us to take the photographs for one day. Other sites were not re-photographed due to the location being unsafe, (e.g. highway shoulder or blind curve). Out of the 11 sites photographed, 4 were discarded for reasons including: the atmosphere of the recent photograph rendered turbines virtually invisible, the original photograph included turbines that were barely visible due to distance, or in the intervening 15 years vegetation removed them from view completely.

\section{Economic Benefits}

- Created 200 jobs during the construction of the wind turbines and 6 permanent staff technician jobs.

\section{Methods:}

Press release by Avangrid Renewables was used to ascertain the number of jobs created during the construction of the wind farm. The press release revealed that as a contribution to a 
rise to local employment during the construction operation, the project provided 200 temporary employment opportunities for local residents.

\section{Sources:}

Avangrid Renewables, 2010. "New York's Newest Wind Farm Now Under Construction", Press Release https://www.avangridrenewables.com/wps/portal/aren/footer/!ut/p/z1/jVDBCoJAFPyWDp3fykroc YIYLTWKLHsXWWILQ3fVIYivj0rqe80AzNvhgGEHFCJd kUfamVqCy 4aagTrwL3C1JPEYZSQ 07HtJGhwDB64DQez6JHVp IHF-4VYJuMRP hwiy wTApxv58LsAuUr7ZFBniXapefHnLRSVU0nTSm07pekxGUIRRGmgG1ZXEQN55rrnBTZ1n-iR6nkK1WD4v6w!!/?1dmy\&current=true\&urile=wcm\%3Apath\%3A\%2FAREN PressRoom\%2FPressRoo m\%2FPressReleases\%2FHistorical News Section\%2FNew\%2BYorks\%2BNewest\%2BWind\% 2BFarm\%2BNow\%2BUnder\%2BConstruction

Limitations:

Source is somewhat dated and would benefit from further sources backing up this information.

\section{- Generates an average $\$ 650,000$ of income annually through lease payments to landowners providing acreage for wind turbines on farmland.}

\section{Methods:}

A press release by Avangrid Renewables was located to ascertain the annual income generated by the project. It was found that additional income generated by lease payments from the project sponsor to individual land owners across the project site stimulate the local economy and support small-scale agriculture.

Sources:

Avangrid Renewables, 2010. "New York's Newest Wind Farm Now Under Construction”, Press Release https://www.avangridrenewables.com/wps/portal/aren/footer/!ut/p/z1/jVDBCoJAFPyWDp3fykroc YIYLTWKLHSXWWILQ3fVIYivi0rae80AzNvhgGEHFCJd kUfamVqCy 4aagTrwL3C1JPEYZSQ 07HtJGhwDB64DQez6JHVp IHF-4VYJuMRP hwiy wTApxv58LsAuUr7ZFBnjXqpefHnLRSVU0nTSm07pekxGUIRRGmgG1ZXEQN55rrnBTZ1n-iR6nkK1WD4v6w!!/?1dmy\&current=true\&urile=wcm\%3Apath\%3A\%2FAREN PressRoom\%2FPressRoo m\%2FPressReleases\%2FHistorical News Section\%2FNew\%2BYorks\%2BNewest\%2BWind\% 2BFarm\%2BNow\%2BUnder\%2BConstruction 


\section{Limitations:}

Source is outdated, and it is possible that lease payments have changed since 2010 . No public data is available on the ongoing terms of the lease payments for the wind farm. 